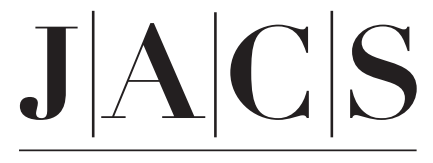

A R T I C L E S

Published on Web 12/13/2007

\title{
Interconvertable Modular Framework and Layered Lanthanide(III)-Etidronic Acid Coordination Polymers
}

\author{
F. N. Shi, ${ }^{\dagger}$ L. Cunha-Silva, ${ }^{\dagger}$ R. A. Sá Ferreira,${ }^{\ddagger}$ L. Mafra ${ }^{\dagger}{ }^{\dagger}$. Trindade $^{\dagger}$ \\ L. D. Carlos, ${ }^{\ddagger}$ F. A. Almeida Paz, ${ }^{*}$, and J. Rocha ${ }^{*} \dagger$ \\ Contribution from the Department of Chemistry, CICECO, University of Aveiro, \\ 3810-193 Aveiro, Portugal, Department of Physics, CICECO, University of Aveiro, \\ 3810-193 Aveiro, Portugal
}

Received June 6, 2007; E-mail: rocha@ua.pt; filipe.paz@ua.pt

\begin{abstract}
Isostructural modular microporous $\mathrm{Na}_{2}\left[\mathrm{Y}(\right.$ hedp $\left.)\left(\mathrm{H}_{2} \mathrm{O}\right)_{0.67}\right]$ and $\mathrm{Na}_{4}\left[\mathrm{Ln}_{2}(\text { hedp })_{2}\left(\mathrm{H}_{2} \mathrm{O}\right)_{2}\right] \cdot n \mathrm{H}_{2} \mathrm{O}(\mathrm{Ln}$ $=\mathrm{La}, \mathrm{Ce}, \mathrm{Nd}, \mathrm{Eu}, \mathrm{Gd}, \mathrm{Tb}, \mathrm{Er})$ framework-type, and layered orthorhombic $\left[\mathrm{Eu}\left(\mathrm{H}_{2} \mathrm{hedp}\right)\left(\mathrm{H}_{2} \mathrm{O}\right)_{2}\right] \cdot \mathrm{H}_{2} \mathrm{O}$ and $\mathrm{Na}_{0.9}\left[\mathrm{Nd}_{0.9} \mathrm{Ge}_{0.10}(\mathrm{Hhedp})\left(\mathrm{H}_{2} \mathrm{O}\right)_{2}\right]$, monoclinic $\left[\mathrm{Ln}\left(\mathrm{H}_{2}\right.\right.$ hedp) $\left.\left(\mathrm{H}_{2} \mathrm{O}\right)\right] \cdot 3 \mathrm{H}_{2} \mathrm{O}(\mathrm{Ln}=\mathrm{Y}, \mathrm{Tb})$, and triclinic $\left[\mathrm{Yb}\left(\mathrm{H}_{2^{-}}\right.\right.$ hedp)] $\cdot \mathrm{H}_{2} \mathrm{O}$ coordination polymers based on etidronic acid $\left(\mathrm{H}_{5}\right.$ hedp) have been prepared by hydrothermal synthesis and characterized structurally by (among others) single-crystal and powder X-ray diffraction and solid-state NMR. The structure of the framework materials comprises eight-membered ring channels filled with $\mathrm{Na}^{+}$and both free and lanthanide-coordinated water molecules, which are removed reversibly by calcination at $300^{\circ} \mathrm{C}$ (structural integrity is preserved up to ca. $475^{\circ} \mathrm{C}$ ), denoting a clear zeolite-type behavior. Interesting photoluminescence properties, sensitive to the hydration degree, are reported for $\mathrm{Na}_{4}\left[\mathrm{Eu}_{2}(\text { hedp) })^{-}\right.$ $\left.\left(\mathrm{H}_{2} \mathrm{O}\right)_{2}\right] \cdot \mathrm{H}_{2} \mathrm{O}$ and its fully dehydrated form. The $3 \mathrm{D}$ framework and layered materials are, to a certain extent, interconvertable during the hydrothermal synthesis stage via the addition of $\mathrm{HCl}$ or $\mathrm{NaCl}$ : of the $3 \mathrm{D}$ framework $\mathrm{Na}_{4}\left[\mathrm{~Tb}_{2}(\text { hedp })_{2}\left(\mathrm{H}_{2} \mathrm{O}\right)_{2}\right] \cdot n \mathrm{H}_{2} \mathrm{O}$, affords layered $\left[\mathrm{Tb}\left(\mathrm{H}_{2}\right.\right.$ hedp $\left.)\left(\mathrm{H}_{2} \mathrm{O}\right)\right] \cdot 3 \mathrm{H}_{2} \mathrm{O}$, whereas layered $\left[\mathrm{Tb}\left(\mathrm{H}_{2^{-}}\right.\right.$ hedp) $\left.\left(\mathrm{H}_{2} \mathrm{O}\right)_{2}\right] \cdot \mathrm{H}_{2} \mathrm{O}$ reacts with sodium chloride yielding a material similar to $\mathrm{Na}_{4}\left[\mathrm{~Tb}_{2}(\text { hedp })_{2}\left(\mathrm{H}_{2} \mathrm{O}\right)_{2}\right] \cdot n \mathrm{H}_{2} \mathrm{O}$. In layered $\left[\mathrm{Y}\left(\mathrm{H}_{2}\right.\right.$ hedp $\left.)\left(\mathrm{H}_{2} \mathrm{O}\right)\right] \cdot 3 \mathrm{H}_{2} \mathrm{O}$, noncoordinated water molecules are engaged in cooperative waterto-water hydrogen-bonding interactions, leading to the formation of a $\left(\mathrm{H}_{2} \mathrm{O}\right)_{13}$ cluster, which is the basis of an unprecedented two-dimensional water network present in the interlayer space.
\end{abstract}

\section{Introduction}

Metal-organic microporous framework materials (MOFs) are of considerable scientific interest because the combination of inorganic and organic fragments (primary building units, PBUs) can produce an endless number of new crystal architectures ${ }^{1,2}$ and allows the design of solids with specific functions. ${ }^{3}$

\footnotetext{
$\dagger$ Department of Chemistry.
}

Department of Physics.

(1) (a) Champness, N. R. Making Coordination Frameworks. In Making Crystals by Design - Methods, Techniques and Applications, 1st ed.; Braga, D., Grepioni, F., Eds.; Wiley-VCH Verlag: Weinheim, 2007; pp 193208. (b) Batten, S. R.; Robson, R. Angew. Chem., Int. Ed. 1998, 37, 14611494. (c) Devic, T.; Serre, C.; Audebrand, N.; Marrot, J.; Ferey, G. J. Am. Chem. Soc. 2005, 127, 12788-12789. (d) Ferey, G.; Mellot-Draznieks, C.; Serre, C.; Millange, F.; Dutour, J.; Surble, S.; Margiolaki, I. Science 2005, 309, 2040-2042. (e) Guillou, O.; Daiguebonne, C. Lanthanidecontaining Coordination Polymers. In Handbook on the Physics and Chemistry of Rare Earths; Gschneidner, K. A., Bunzli, J.-C. G., Pecharsky, V. K., Eds.; Elsevier: New York, 2005; Vol. 34, pp 359-404. (f) Janiak, C. Dalton Trans. 2003, 2781-2804. (g) Kesanli, B.; Lin, W. B. Coord. Chem. Rev. 2003, 246, 305-326. (h) Kitagawa, S.; Uemura, K. Chem. Soc. Rev. 2005, 34, 109-119. (i) Lebedev, O. I.; Millange, F.; Serre, C.; Van Tendeloo, G.; Ferey, G. Chem. Mater. 2005, 17, 6525-6527. (j) Livage, C.; Guillou, N.; Chaigneau, J.; Rabit, P.; Drillon, M.; Ferey, G. Angew. Chem., Int. Ed. 2005, 44, 6488-6491. (k) Matczak-Jon, E.; Videnova-Adrabinska, V. Coord. Chem. Rev. 2005, 249, 2458-2488. (l) Papaefstathiou, G. S.; MacGillivray, L. R. Coord. Chem. Rev. 2003, 246, 169-184. (m) Rowsell, J. L. C.; Yaghi, O. M. Microporous Mesoporous Mater. 2004, 73, 3-14. (n) Ye, B. H.; Tong, M. L.; Chen, X. M. Coord. Chem. Rev. 2005, 249, 545-565. (o) Zaworotko, M. J. Chem. Commun. 2001, 1-9.

(2) (a) Carlucci, L.; Ciani, G.; Proserpio, D. M. Coord. Chem. Rev. 2003, 246 , 247-289. (b) Carlucci, L.; Ciani, G.; Proserpio, D. M. CrystEngComm 2003, 5, 269-279.

150 - J. AM. CHEM. SOC. 2008, 130, 150-167
Interesting properties which may lead to industrial applications include gas storage and separation, ${ }^{4,5}$ catalysis, ${ }^{5,6}$ guestexchange, ${ }^{7}$ and sensors based on optical and magnetic properties. ${ }^{8}$ However, the considerable structural diversity found in

(3) (a) Chae, H. K.; Siberio-Perez, D. Y.; Kim, J.; Go, Y.; Eddaoudi, M.; Matzger, A. J.; O'Keeffe, M.; Yaghi, O. M. Nature 2004, 427, 523-527. (b) Chen, B. L.; Eddaoudi, M.; Hyde, S. T.; O'Keeffe, M.; Yaghi, O. M. Science 2001, 291, 1021-1023. (c) Cote, A. P.; Benin, A. I.; Ockwig, N. W.; O'Keeffe, M.; Matzger, A. J.; Yaghi, O. M. Science 2005, 310, $1166-$ 1170. (d) Kepert, C. J. Chem. Commun. 2006, 695-700. (e) Kitagawa, S.; Kitaura, R.; Noro, S. Angew. Chem., Int. Ed. 2004, 43, 2334-2375. (f) Li, H.; Eddaoudi, M.; O'Keeffe, M.; Yaghi, O. M. Nature 1999, 402, 276279. (g) Yaghi, O. M.; O'Keeffe, M.; Ockwig, N. W.; Chae, H. K.; Eddaoudi, M.; Kim, J. Nature 2003, 423, 705-714.

(4) (a) Eddaoudi, M.; Kim, J.; Rosi, N.; Vodak, D.; Wachter, J.; O'Keefe, M.; Yaghi, O. M. Science 2002, 295, 469-472. (b) Eddaoudi, M.; Li, H. L.; Yaghi, O. M. J. Am. Chem. Soc. 2000, 122, 1391-1397. (c) Jhung, S. H.; Lee, J. H.; Yoon, J. W.; Serre, C.; Ferey, G.; Chang, J. S. Adv. Mater. 2007, 19, 121. (d) Jia, J. H.; Lin, X.; Wilson, C.; Blake, A. J.; Champness, N. R.; Hubberstey, P.; Walker, G.; Cussen, E. J.; Schroder, M. Chem Commun. 2007, 840-842. (e) Latroche, M.; Surble, S.; Serre, C.; MellotDraznieks, C.; Llewellyn, P. L.; Lee, J. H.; Chang, J. S.; Jhung, S. H.; Ferey, G. Angew. Chem., Int. Ed. 2006, 45, 8227-8231. (f) Loiseau, T.; Lecroq, L.; Volkringer, C.; Marrot, J.; Ferey, G.; Haouas, M.; Taulelle, F. Bourrelly, S.; Llewellyn, P. L.; Latroche, M. J. Am. Chem. Soc. 2006, 128, 10223-10230. (g) Ramsahye, N. A.; Maurin, G.; Bourrelly, S.; Llewellyn, P.; Loiseau, T.; Ferey, G. Phys. Chem. Chem. Phys. 2007, 9, 1059-1063. (h) Rosi, N. L.; Eckert, J.; Eddaoudi, M.; Vodak, D. T.; Kim, J.; O'Keeffe, M.; Yaghi, O. M. Science 2003, 300, 1127-1129. (i) Rowsell, J. L. C. Spencer, E. C.; Eckert, J.; Howard, J. A. K.; Yaghi, O. M. Science 2005 309, 1350-1354. (j) Surble, S.; Millange, F.; Serre, C.; Duren, T.; Latroche, M.; Bourrelly, S.; Llewellyn, P. L.; Ferey, G. J. Am. Chem. Soc. 2006 128, 14889-14896. (k) Yaghi, O. M.; Li, G. M.; Li, H. L. Nature 1995, 378, 703-706.

(5) Chui, S. S. Y.; Lo, S. M. F.; Charmant, J. P. H.; Orpen, A. G.; Williams, I. D. Science 1999, 283, 1148-1150.

10.1021/ja074119k CCC: $\$ 40.75 \odot 2008$ American Chemical Society 
this family of materials contrasts with the lack of successful prediction paths for the PBUs self-assembly ${ }^{9}$ which leads to porous materials. This supramolecular isomerism ${ }^{10}$ may be, at least to some extent, minimized by assembling rigid secondary building units (SBUs) ${ }^{11}$ with a number of remarkable structures being recently unveiled by the combined use of computational approaches of assembly of SBUs with high-resolution powder X-ray diffraction data. ${ }^{12}$ Nevertheless, only ca. $10 \%$ of MOFs are effectively microporous and exhibit zeolite-type behavior, such as reversible solvent sorption, ion-exchange capacity, and thermal stability. Outstanding examples include the MIL-88 family. ${ }^{13}$ Recently, the preparation of photoluminescent lanthanides-based MOFs gained some impetus. ${ }^{14}$ In these materials, the lanthanides centers (often in the trivalent state) act as network nodes bridged, essentially, by di- or polycarboxylatesbased spacer ligands. In contrast, phosphonate-based linkers have been primarily used with transition metal centers or $p$-block elements, such as aluminum, to produce porous materials. ${ }^{15}$ Only a few MOFs have been reported to combine zeolitic microporosity and lanthanide ions, which may display photoluminescence properties. To our knowledge, none of these materials are built up from chelating organic PBUs purely based on phosphonic acid groups.

Following our ongoing research on MOFs, ${ }^{16}$ here we wish to report a series of novel modular multidimensional rare-earth organic frameworks (REOFs) using as PBUs lanthanide centers and etidronic acid $\left(\mathrm{H}_{5}\right.$ hedp): framework-type $\mathrm{Na}_{2}$ [Y(hedp)$\left.\left(\mathrm{H}_{2} \mathrm{O}\right)_{0.67}\right]$ (1a) and $\mathrm{Na}_{4}\left[\mathrm{Ln}_{2}(\text { hedp })_{2}\left(\mathrm{H}_{2} \mathrm{O}\right)_{2}\right] \cdot n \mathrm{H}_{2} \mathrm{O}[\mathrm{Ln}=\mathrm{La}(\mathbf{1 b})$, $\mathrm{Ce}(\mathbf{1 c}), \mathrm{Nd}(\mathbf{1 d}), \mathrm{Eu}(\mathbf{1 e}), \mathrm{Gd}(\mathbf{1 f}), \mathrm{Tb}(\mathbf{1 g})$, and $\mathrm{Er}(\mathbf{1 h})]$, layered orthorhombic $\left[\mathrm{Eu}\left(\mathrm{H}_{2}\right.\right.$ hedp $\left.)\left(\mathrm{H}_{2} \mathrm{O}\right)_{2}\right] \cdot \mathrm{H}_{2} \mathrm{O}(\mathbf{2 a})$ and $\mathrm{Na}_{0.9}\left[\mathrm{Nd}_{0.9^{-}}\right.$ $\left.\mathrm{Ge}_{0.10}(\mathrm{Hhedp})\left(\mathrm{H}_{2} \mathrm{O}\right)_{2}\right]$ (2b), monoclinic $\left[\mathrm{M}\left(\mathrm{H}_{2}\right.\right.$ hedp $\left.)\left(\mathrm{H}_{2} \mathrm{O}\right)\right] \cdot$ $3 \mathrm{H}_{2} \mathrm{O} \quad[\mathrm{M}=\mathrm{Y}(\mathbf{3 a}), \quad \mathrm{Tb}(\mathbf{3 b})]$, and triclinic $\left[\mathrm{Yb}\left(\mathrm{H}_{2-}\right.\right.$

(6) (a) Evans, O. R.; Ngo, H. L.; Lin, W. B. J. Am. Chem. Soc. 2001, 123 , 10395-10396. (b) Fujita, M.; Kwon, Y. J.; Washizu, S.; Ogura, K. J. Am Chem. Soc. 1994, 116, 1151-1152. (c) Seo, J. S.; Whang, D.; Lee, H.; Jun, S. I.; Oh, J.; Jeon, Y. J.; Kim, K. Nature 2000, 404, 982-986.

(7) Maji, T. K.; Mukherjee, P. S.; Mostafa, G.; Zangrando, E.; Chaudhuri, N. R. Chem. Commun. 2001, 1368-1369.

(8) (a) Hagrman, P. J.; Hagrman, D.; Zubieta, J. Angew. Chem., Int. Ed. 1999 38, 2639-2684. (b) Halder, G. J.; Kepert, C. J.; Moubaraki, B.; Murray, K. S.; Cashion, J. D. Science 2002, 298, 1762-1765. (c) Kahn, O. Acc. Chem. Res. 2000, 33, 647-657.

(9) Dunitz, J. D. Chem. Commun. 2003, 545-548.

(10) Moulton, B.; Zaworotko, M. J. Chem. Rev. 2001, 101, 1629-1658.

(11) Yaghi, O. M.; Li, H. L.; Davis, C.; Richardson, D.; Groy, T. L. Acc. Chem. Res. 1998, 31, 474-484.

(12) (a) Ferey, G.; Mellot-Draznieks, C.; Serre, C.; Millange, F. Acc. Chem Res. 2005, 38, 217-225. (b) Ferey, G.; Serre, C.; Mellot-Draznieks, C.; Millange, F.; Surble, S.; Dutour, J.; Margiolaki, I. Angew. Chem., Int. Ed. 2004, 43, 6296-6301. (c) Mellot-Draznieks, C.; Ferey, G. Prog. Solid State Chem. 2005, 33, 187-197. (d) Mellot-Draznieks, C.; Serre, C.; Surble, S.; Audebrand, N.; Ferey, G. J. Am. Chem. Soc. 2005, 127, 16273-16278.

(13) (a) Serre, C.; Mellot-Draznieks, C.; Surble, S.; Audebrand, N.; Filinchuk, Y.; Ferey, G. Science 2007, 315, 1828-1831. (b) Surble, S.; Serre, C.; Mellot-Draznieks, C.; Millange, F.; Ferey, G. Chem. Commun. 2006, 284286.

(14) (a) Hill, R. J.; Long, D. L.; Champness, N. R.; Hubberstey, P.; Schroder, M. Acc. Chem. Res. 2005, 38, 335-348. (b) Hill, R. J.; Long, D. L.; Hubberstey, P.; Schroder, M.; Champness, N. R. J. Solid State Chem. 2005 178, 2414-2419. (c) Hill, R. J.; Long, D. L.; Turvey, M. S.; Blake, A. J.; Champness, N. R.; Hubberstey, P.; Wilson, C.; Schroder, M. Chem. Commun. 2004, 1792-1793. (d) Long, D. L.; Blake, A. J.; Champness, N. R.; Schroder, M. Chem. Commun. 2000, 1369-1370. (e) Long, D. L.; Blake, A. J.; Champness, N. R.; Wilson, C.; Schroder, M. Angew. Chem., Int. Ed. 2001, 40, 2444. (f) Long, D. L.; Blake, A. J.; Champness, N. R.; Wilson, C.; Schroder, M. Chem.-Eur. J. 2002, 8, 2026-2033.

(15) (a) Groves, J. A.; Miller, S. R.; Warrender, S. J.; Mellot-Draznieks, C Lightfoot, P.; Wright, P. A. Chem. Commun. 2006, 3305-3307. (b) Hix, G. B.; Carter, V. J.; Wragg, D. S.; Morris, R. E.; Wright, P. A. J. Mater. Chem. 1999, 9, 179-185. (c) Carter, V. J.; Wright, P. A.; Gale, J. D. Morris, R. E.; Sastre, E.; PerezPariente, J. J. Mater. Chem. 1997, 7, 22872292. (d) Maeda, K.; Akimoto, J.; Kiyozumi, Y.; Mizukami, F. Angew. Chem., Int. Ed. Engl. 1995, 34, 1199-1201.(e) Maeda, K.; Akimoto, J.; Kiyozumi, Y.; Mizukami, F. Chem. Commun. 1995, 1033-1034. hedp)] $\cdot \mathrm{H}_{2} \mathrm{O}(4)$ (Scheme 1$)$. These materials exhibit three main unusual structural features. First, the framework materials combine zeolite-type behavior (reversible adsorption-desorption of water molecules residing in the channels and potential ion exchange of extraframework $\mathrm{Na}^{+}$cations) with photoluminescence properties (improved by removing the water molecule coordinated to the lanthanide), here illustrated for the $\mathrm{Eu}^{3+}$ containing material, 1e. Second, framework and layered materials are, to a certain extent, interconvertable at the hydrothermal synthetic stage via the addition of $\mathrm{HCl}$ or sodium chloride. For example, the $\mathrm{HCl}$ treatment of $\mathbf{1 g}$, under hydrothermal conditions, affords $\mathbf{3} \mathbf{b}$, whereas a $\mathrm{Tb}^{3+}$ analogue of $\mathbf{2} \mathbf{a}$ reacts with sodium chloride (hydrothermally), yielding a material similar to $\mathbf{1 g}$ (Scheme 1). Third, in layered $\mathbf{3 a}$, noncoordinated water molecules are engaged in cooperative water-to-water hydrogenbonding interactions, leading to the formation of a $\left(\mathrm{H}_{2} \mathrm{O}\right)_{13}$ cluster, which is the basis of an unprecedented two-dimensional water network.

\section{Experimental Section}

Synthesis. Reagents were readily available from commercial sources and were used as received without further purification: germanium(IV) oxide $\left(\mathrm{GeO}_{2}, 99.99+\%\right.$, Aldrich), 1-hydroxyethylidenediphosphonic acid tetrasodium salt $\left(\mathrm{Na}_{4} \mathrm{Hhedp}, \mathrm{C}_{2} \mathrm{H}_{4} \mathrm{Na}_{4} \mathrm{O}_{7} \mathrm{P}_{2}, \geq 90 \%\right.$, Fluka), 1-hydroxyethylidenediphosphonic acid $\left(\mathrm{H}_{5}\right.$ hedp, $\mathrm{C}_{2} \mathrm{H}_{8} \mathrm{O}_{7} \mathrm{P}_{2}, \geq 97 \%$, Fluka), terephthalic acid $\left(\mathrm{C}_{8} \mathrm{H}_{6} \mathrm{O}_{4}, \geq 99 \%\right.$, Fluka), succinic acid (HOOC$\left(\mathrm{CH}_{2}\right)_{2} \mathrm{COOH}, 99.5 \%$, Carlo Erba), and lanthanides (III) chloride hydrates $\left(\mathrm{LaCl}_{3} \cdot 7 \mathrm{H}_{2} \mathrm{O}, \mathrm{CeCl}_{3} \cdot 7 \mathrm{H}_{2} \mathrm{O}, \mathrm{NdCl}_{3} \cdot 6 \mathrm{H}_{2} \mathrm{O}, \mathrm{EuCl}_{3} \cdot 6 \mathrm{H}_{2} \mathrm{O}, \mathrm{GdCl}_{3} \cdot\right.$ $6 \mathrm{H}_{2} \mathrm{O}, \mathrm{TbCl}_{3} \cdot 6 \mathrm{H}_{2} \mathrm{O}, \mathrm{ErCl}_{3} \cdot 6 \mathrm{H}_{2} \mathrm{O}, \mathrm{YbCl}_{3} \cdot 6 \mathrm{H}_{2} \mathrm{O}$ and $\mathrm{YCl}_{3} \cdot 6 \mathrm{H}_{2} \mathrm{O}, \geq 99.9 \%$, Aldrich).

Framework $\mathrm{Na}_{2}\left[\mathbf{Y}\left(\right.\right.$ hedp) $\left.\left(\mathrm{H}_{2} \mathrm{O}\right)_{\mathbf{0 . 6 7}}\right]$ (1a). A mixture of $0.242 \mathrm{~g}$ of $\mathrm{Na}_{4} \mathrm{Hhedp}$ (1.06 mmol), $0.200 \mathrm{~g}$ of $\mathrm{YCl}_{3} \cdot 6 \mathrm{H}_{2} \mathrm{O}(0.66 \mathrm{mmol}), 0.170 \mathrm{~g}$ of $\mathrm{GeO}_{2}(1.62 \mathrm{mmol})$, and $0.28 \mathrm{~g}$ of $\mathrm{HOOC}\left(\mathrm{CH}_{2}\right)_{2} \mathrm{COOH}(2.37 \mathrm{mmol})$ in ca. $15 \mathrm{~g}$ of distilled water was stirred half an hour to homogeneity. The hydrothermal reaction was carried out at $150^{\circ} \mathrm{C}$ for 3 days. The product was a mixture of single crystals of $\mathbf{1 a}(0.120 \mathrm{~g}$, yield of ca. $52 \%$ based on $\mathrm{YCl}_{3} \cdot 6 \mathrm{H}_{2} \mathrm{O}$ ) and fine particles, which were separated by ultrasonication. The addition of succinic acid was needed to keep the value of the gel between 2 and 3 (of about 2.6 for this reaction). Even though the dicarboxylic acid was not included in the final product, its inclusion in the reactive mixture is crucial to isolate good-quality single crystals of 1a. In fact, similar reactions without addition of the dicarboxylic acid led to amorphous powders. Single crystals of $\mathbf{1 h}$ were obtained under $\left(0.130 \mathrm{~g}\right.$, yield of ca. $40 \%$ based on $\left.\mathrm{ErCl}_{3} \cdot 6 \mathrm{H}_{2} \mathrm{O}\right)$ the same conditions by using $0.290 \mathrm{~g}$ of $\mathrm{ErCl}_{3} \cdot 6 \mathrm{H}_{2} \mathrm{O}$ instead of $\mathrm{YCl}_{3} \cdot 6 \mathrm{H}_{2} \mathrm{O}$. Elemental analysis: Calcd $(\%)$ for $\mathrm{C}_{2} \mathrm{H}_{7.33} \mathrm{O}_{7.67} \mathrm{P}_{2} \mathrm{Na}_{2} \mathrm{Y}$ (MW $=$ 350.92): C 6.84, H 2.09; Found: $\mathrm{C}$ 7.01, H 2.71. Calcd (\%) for $\mathrm{C}_{2} \mathrm{H}_{5} \mathrm{O}_{8} \mathrm{P}_{2} \mathrm{Na}_{2} \mathrm{Er}(\mathrm{MW}=432.18):$ C 5.55, H 1.16; Found: $\mathrm{C} 5.33, \mathrm{H}$ 1.70. Selected FT-IR (KBr pellets) and Raman main bands (inside the

(16) (a) Cunha-Silva, L.; Mafra, L.; Ananias, D.; Carlos, L. D.; Rocha, J.; Paz, F. A. A. Chem. Mater. 2007, 19, 3527-3538. (b) Girginova, P. I.; Paz, F. A. A.; Nogueira, H. I. S.; Silva, N. J. O.; Amaral, V. S.; Klinowski, J.; Trindade, T. Polyhedron 2005, 24, 563-569. (c) Girginova, P. I.; Paz, F. A. A.; Nogueira, H. I. S.; Silva, N. J. O.; Amaral, V. S.; Klinowski, J.; Trindade, T. J. Mol. Struct. 2005, 737, 221-229. (d) Paz, F. A. A.; Klinowski, J. J. Phys. Org. Chem. 2003, 16, 772-782. (e) Paz, F. A. A.; Klinowski, J. Chem. Commun. 2003, 1484-1485. (f) Paz, F. A. A Klinowski, J. J. Solid State Chem. 2004, 177, 3423-3432. (g) Paz, F. A. A.; Klinowski, J. Inorg. Chem. 2004, 43, 3882-3893. (h) Paz, F. A. A.; Klinowski, J. Inorg. Chem. 2004, 43, 3948-3954. (i) Paz, F. A. A.; Klinowski, J. Pure Appl. Chem. 2007, 79, 1097-1110. (j) Paz, F. A. A.; Rocha, J.; Klinowski, J.; Trindade, T.; Shi, F. N.; Mafra, L. Prog. Solid State Chem. 2005, 33, 113-125. (k) Paz, F. A. A.; Shi, F. N.; Klinowski, J.; Rocha, J.; Trindade, T. Eur. J. Inorg. Chem. 2004, 2759-2768. (1) Shi, F. N.; Paz, F. A. A.; Girginova, P.; Rocha, J.; Amaral, V. S.; Klinowski, J.; Trindade, T. J. Mol. Struct. 2006, 789, 200-208. (m) Shi, F. N.; Paz, F. A. A.; Girginova, P. I.; Mafra, L.; Amaral, V. S.; Rocha, J.; Makal, A.; Wozniak, K.; Klinowski, J.; Trindade, T. J. Mol. Struct. 2005, 754, $51-$ 60 
Scheme 1. Hydrothermal Synthetic Approach Leading to the Isolation of the 2- and 3D Rare-Earth Organic Frameworks (REOFs), Starting from Their Primary Building Units, and the Interconvertable Synthetic Routes between 2- and 3D Coordination Polymers

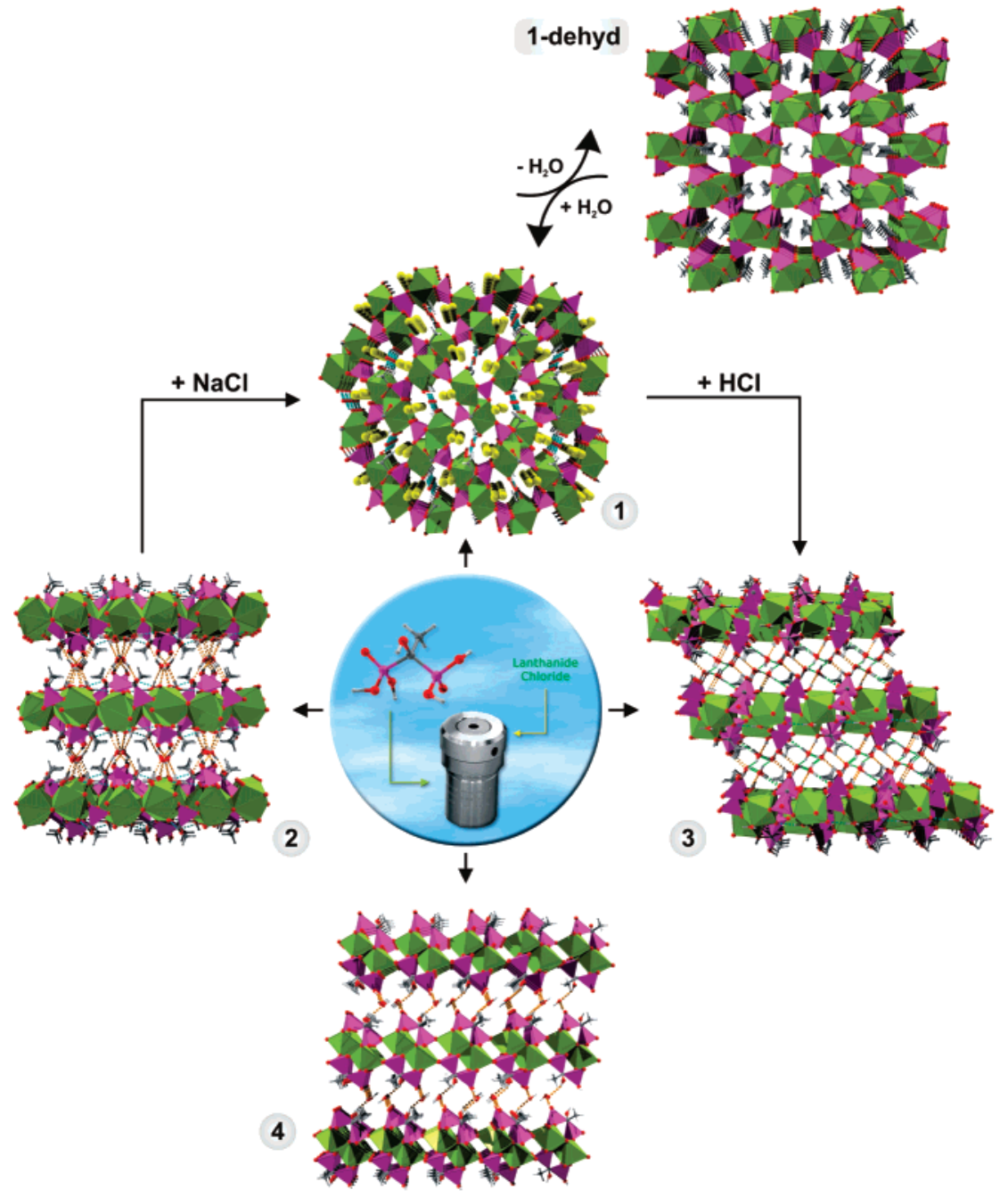

parenthesis in italics) (in $\left.\mathrm{cm}^{-1}\right)$ : for $\mathbf{1 a}, v(\mathrm{O}-\mathrm{H}$ water $)=3408 \mathrm{vs} / \mathrm{br}$ $(3351 \mathrm{w} / \mathrm{br}), \delta(\mathrm{O}-\mathrm{H}$ water $)=1663 \mathrm{~m}, v_{\text {asym }}\left(\mathrm{P}-\mathrm{O}_{\text {coord }}\right)=1099 \mathrm{vs} / \mathrm{br}$ $(1086 v s), v_{\text {sym }}\left(\mathrm{P}-\mathrm{O}_{\text {coord }}\right)=1012,977$ vs $(1011,961 w)$; for $\mathbf{1 h}, v$ $(\mathrm{O}-\mathrm{H}$ water $)=3408 \mathrm{vs} / \mathrm{br}(3351 \mathrm{w} / \mathrm{br}), \delta(\mathrm{O}-\mathrm{H}$ water $)=1654 \mathrm{~m}$, $v_{\text {asym }}\left(\mathrm{P}-\mathrm{O}_{\text {coord }}\right)=1099 \mathrm{vs} / \mathrm{br}(1086 v s), v_{\text {sym }}\left(\mathrm{P}-\mathrm{O}_{\text {coord }}\right)=1012,977$ vs $(1020,966 \mathrm{w})$. Thermogravimetric analysis (TGA) data (weight losses in \%) and derivative thermogravimetric peaks (DTG; in italics inside the parentheses): (1a) $19-90{ }^{\circ} \mathrm{C}-3.2 \%\left(75^{\circ} \mathrm{C}\right), 90-171{ }^{\circ} \mathrm{C}$ $-3.5 \%\left(160^{\circ} \mathrm{C}\right), 171-230^{\circ} \mathrm{C}-1.5 \%\left(198^{\circ} \mathrm{C}\right), 230-353{ }^{\circ} \mathrm{C}-3.2 \%$ $\left(314{ }^{\circ} \mathrm{C}\right), 353-500{ }^{\circ} \mathrm{C}-2.4 \%\left(434{ }^{\circ} \mathrm{C}\right), 500-588{ }^{\circ} \mathrm{C}+1.7 \%(560$ $\left.{ }^{\circ} \mathrm{C}\right)$, and $588-700{ }^{\circ} \mathrm{C}-4.8 \%\left(615^{\circ} \mathrm{C}\right)$; (1h) $23-90{ }^{\circ} \mathrm{C}-2.6 \%(62$ $\left.{ }^{\circ} \mathrm{C}\right), 90-201{ }^{\circ} \mathrm{C}-3.6 \%\left(158\right.$ and $\left.188^{\circ} \mathrm{C}\right), 201-356^{\circ} \mathrm{C}-2.6 \%(324$ $\left.{ }^{\circ} \mathrm{C}\right)$, and $356-500{ }^{\circ} \mathrm{C}-1.8 \%\left(449{ }^{\circ} \mathrm{C}\right)$.

Framework $\mathrm{Na}_{4}\left[\operatorname{Ln}_{2}(\text { hedp })_{2}\left(\mathrm{H}_{2} \mathrm{O}\right)_{2}\right] \cdot \mathbf{n H}_{2} \mathrm{O}$ (1b to $\left.1 \mathrm{~g}\right)$. Because these six compounds are obtained by adopting the same synthetic procedure, only the synthesis of $\mathbf{1 e}$ is depicted in detail. A mixture of $0.940 \mathrm{~g}$ of $\mathrm{Na}_{4} \mathrm{Hhedp}(3.79 \mathrm{mmol}), 0.350 \mathrm{~g}$ of $\mathrm{EuCl}_{3} \cdot 6 \mathrm{H}_{2} \mathrm{O}(0.94 \mathrm{mmol})$, and $0.160 \mathrm{~g}$ of $\mathrm{GeO}_{2}(1.53 \mathrm{mmol})$ in ca. $15 \mathrm{~g}$ of distilled water was stirred thoroughly for $30 \mathrm{~min}$ at room temperature yielding a suspension with a molar composition of 4.03:1.00:1.63:940, respectively. The homogeneous suspension was moved to a PTFE-lined stainless steel reaction vessel $(40 \mathrm{~mL})$, which was placed under autogenous pressure and static conditions in a preheated oven at $150{ }^{\circ} \mathrm{C}$. The reaction took place over a period of 3 days, after which the vessel was removed from the oven and allowed to cool slowly to ambient temperature before opening. Large single crystals were manually harvested (after dried, $0.390 \mathrm{~g}$, ca. $96 \%$ yield based on $\mathrm{EuCl}_{3} \cdot 6 \mathrm{H}_{2} \mathrm{O}$ ) with a small amount of a white powder. The impurity was readily removed by ultrasonication and filtration. Crystals were washed with copious amounts of distilled water $(3 \times 50 \mathrm{~mL})$ and air-dried at ambient temperature. Elemental analysis: Calcd (\%) for $\mathrm{C}_{4} \mathrm{H}_{12} \mathrm{O}_{17} \mathrm{P}_{4} \mathrm{Na}_{4} \mathrm{La}_{2}(\mathrm{MW}=825.80)$ ): C 5.82, H 1.45; Found: C 5.77, H 2.33. Calcd (\%) for $\mathrm{C}_{4} \mathrm{H}_{12} \mathrm{O}_{17} \mathrm{P}_{4} \mathrm{Na}_{4} \mathrm{Ce}_{2}$ (MW $=828.20)$ : C 5.80, H 1.45; Found: C 5.27, H 2.23. Calcd (\%) for $\mathrm{C}_{4} \mathrm{H}_{12} \mathrm{O}_{17} \mathrm{P}_{4} \mathrm{Na}_{4} \mathrm{Nd}_{2}(\mathrm{MW}=836.46)$ : C 5.74, $\mathrm{H}$ 1.43; Found: $\mathrm{C} 5.72$, $\mathrm{H}$ 2.31. Calcd (\%) for $\mathrm{C}_{4} \mathrm{H}_{11} \mathrm{O}_{16.50} \mathrm{P}_{4} \mathrm{Na}_{4} \mathrm{Eu}_{2}(\mathrm{MW}=842.89)$ : C 5.69, $\mathrm{H}$ 1.31; Found: C 5.11, $\mathrm{H}$ 1.76. Calcd (\%) for $\mathrm{C}_{4} \mathrm{H}_{10} \mathrm{O}_{16} \mathrm{P}_{4} \mathrm{Na}_{4} \mathrm{Gd}_{2}$ (MW = 844.46): C 5.68, H 1.18; Found: C 5.47, H 2.27. Calcd (\%) for $\mathrm{C}_{4} \mathrm{H}_{11} \mathrm{O}_{16.50} \mathrm{P}_{4} \mathrm{Na}_{4} \mathrm{~Tb}_{2}(\mathrm{MW}=856.81)$ : C 5.60, H 1.28; Found: C 5.24, H 2.25 .

Selected FT-IR ( $\mathrm{KBr}$ pellets) and Raman main bands (inside the parenthesis in italics) (in $\left.\mathrm{cm}^{-1}\right)$ : for $\mathbf{1 b}, v(\mathrm{O}-\mathrm{H}$ water $)=3425 \mathrm{vs} / \mathrm{br}$ $(3366 \mathrm{w} / \mathrm{br}), \delta(\mathrm{O}-\mathrm{H}$ water $)=1637 \mathrm{~m}, v_{\text {asym }}\left(\mathrm{P}-\mathrm{O}_{\text {coord }}\right)=1098 \mathrm{vs} / \mathrm{br}$ $(1104 v s), v_{\text {sym }}\left(\mathrm{P}-\mathrm{O}_{\text {coord }}\right)=1007,967$ vs $(1057,998 w)$; for 1c, $v$ $(\mathrm{O}-\mathrm{H}$ water $)=3417 \mathrm{vs} / \mathrm{br}(3375 \mathrm{w} / \mathrm{br}), \delta(\mathrm{O}-\mathrm{H}$ water $)=1629 \mathrm{~m}$, $v_{\text {asym }}\left(\mathrm{P}-\mathrm{O}_{\text {coord }}\right)=1099 \mathrm{vs} / \mathrm{br}(1124,1081 v \mathrm{~s}), v_{\text {sym }}\left(\mathrm{P}-\mathrm{O}_{\text {coord }}\right)=1004$, $961 \mathrm{vs}(995 \mathrm{w})$; for $1 \mathbf{1 d}, v(\mathrm{O}-\mathrm{H}$ water $)=3417 \mathrm{vs} / \mathrm{br}(3387 \mathrm{w} / \mathrm{br})$, $\delta(\mathrm{O}-\mathrm{H}$ water $)=1628 \mathrm{~m}, v_{\text {asym }}\left(\mathrm{P}-\mathrm{O}_{\text {coord }}\right)=1093 \mathrm{vs} / \mathrm{br}(1096 v s)$, $v_{\text {sym }}\left(\mathrm{P}-\mathrm{O}_{\text {coord }}\right)=1009,968$ vs $(958 w)$; for $\mathbf{1 e}, v(\mathrm{O}-\mathrm{H}$ water $)=3370$ vs $/ \mathrm{br}(3390 w / b r), \delta(\mathrm{O}-\mathrm{H}$ water $)=1634 \mathrm{~m}, v_{\text {asym }}\left(\mathrm{P}-\mathrm{O}_{\text {coord }}\right)=1103$ vs/br $(1082 v s), v_{\text {sym }}\left(\mathrm{P}-\mathrm{O}_{\text {coord }}\right)=1012,961$ vs $(961 w)$; for $\mathbf{1 f}, v$ $(\mathrm{O}-\mathrm{H}$ water $)=3416 \mathrm{vs} / \mathrm{br}(3341 \mathrm{w} / \mathrm{br}), \delta(\mathrm{O}-\mathrm{H}$ water $)=1647 \mathrm{~m}$, $v_{\text {asym }}\left(\mathrm{P}-\mathrm{O}_{\text {coord }}\right)=1108 \mathrm{vs} / \mathrm{br}(1119 v s), v_{\text {sym }}\left(\mathrm{P}-\mathrm{O}_{\text {coord }}\right)=1004,970$ vs $(1002,962 \mathrm{w})$; for $\mathbf{1 g}, v(\mathrm{O}-\mathrm{H}$ water $)=3390 \mathrm{vs} / \mathrm{br}(3383 \mathrm{w} / \mathrm{br})$, 
$\delta(\mathrm{O}-\mathrm{H}$ water $)=1636 \mathrm{~m}, v_{\text {asym }}\left(\mathrm{P}-\mathrm{O}_{\text {coord }}\right)=1117 \mathrm{vs} / \mathrm{br}(1069 \mathrm{vs})$, $v_{\text {sym }}\left(\mathrm{P}-\mathrm{O}_{\text {coord }}\right)=1012,968$ vs $(1011,961 w)$.

TGA data (weight losses in \%) and DTG peaks (in italics inside the parentheses): (1b) $22-110{ }^{\circ} \mathrm{C}-2.2 \%\left(69{ }^{\circ} \mathrm{C}\right), 110-162{ }^{\circ} \mathrm{C}-8.2 \%$ $\left(137^{\circ} \mathrm{C}\right), 162-447^{\circ} \mathrm{C}-2.4 \%\left(331^{\circ} \mathrm{C}\right), 447-500{ }^{\circ} \mathrm{C}-1.1 \%\left(476^{\circ} \mathrm{C}\right)$, and $500-600{ }^{\circ} \mathrm{C}-4.5 \%\left(516{ }^{\circ} \mathrm{C}\right)$; (1c) $20-102{ }^{\circ} \mathrm{C}-1.9 \%\left(56^{\circ} \mathrm{C}\right)$, $102-148{ }^{\circ} \mathrm{C}-8.4 \%\left(130^{\circ} \mathrm{C}\right), 148-504{ }^{\circ} \mathrm{C}-2.6 \%\left(471^{\circ} \mathrm{C}\right)$, and $504-$ $600{ }^{\circ} \mathrm{C}-4.0 \%\left(520^{\circ} \mathrm{C}\right)$; (1d) $31-96{ }^{\circ} \mathrm{C}-1.0 \%\left(65^{\circ} \mathrm{C}\right), 96-167{ }^{\circ} \mathrm{C}$ $-8.2 \%\left(123^{\circ} \mathrm{C}\right), 167-395{ }^{\circ} \mathrm{C}-3.2 \%, 395-523{ }^{\circ} \mathrm{C}-3.6 \%\left(462{ }^{\circ} \mathrm{C}\right)$, $523-600{ }^{\circ} \mathrm{C}-2.3 \%\left(462{ }^{\circ} \mathrm{C}\right)$; (1e) $27-272{ }^{\circ} \mathrm{C}-9.5 \%(76,112,132$, 180 , and $\left.205^{\circ} \mathrm{C}\right), 272-514{ }^{\circ} \mathrm{C}-2.4 \%\left(486^{\circ} \mathrm{C}\right), 514-572{ }^{\circ} \mathrm{C}+0.6 \%$ $\left(548{ }^{\circ} \mathrm{C}\right.$ ), and $572-700{ }^{\circ} \mathrm{C}-1.8 \%$; (1f) $38-143{ }^{\circ} \mathrm{C}-7.7 \%(58,97$ and $\left.134^{\circ} \mathrm{C}\right), 143-511^{\circ} \mathrm{C}-4.5 \%$, and $511-700{ }^{\circ} \mathrm{C}-4.5 \%(531$ and $\left.573{ }^{\circ} \mathrm{C}\right)$; $(\mathbf{1 g}) 26-164{ }^{\circ} \mathrm{C}-8.0 \%\left(63,93\right.$, and $\left.135^{\circ} \mathrm{C}\right), 164-518{ }^{\circ} \mathrm{C}$ $-3.4 \%$, and $518-600{ }^{\circ} \mathrm{C}-4.8 \%\left(542{ }^{\circ} \mathrm{C}\right)$.

Layered $\left[\mathbf{E u}\left(\mathbf{H}_{2}\right.\right.$ hedp) $\left.\left(\mathbf{H}_{2} \mathbf{O}\right)_{2}\right] \cdot\left(\mathbf{H}_{2} \mathbf{O}\right)(\mathbf{2 a})$. A mixture of $0.080 \mathrm{~g}$ of $\mathrm{H}_{5}$ hedp $(0.39 \mathrm{mmol})$ and $0.280 \mathrm{~g}$ of $\mathrm{EuCl}_{3} \cdot 6 \mathrm{H}_{2} \mathrm{O}(0.76 \mathrm{mmol})$ in ca. $13 \mathrm{~g}$ of distilled water was stirred half an hour at ambient temperature to homogeneity. The hydrothermal reaction was carried out at $150{ }^{\circ} \mathrm{C}$ for 4 days under autogenous pressure and static conditions. Single crystals of $2 \mathrm{a}\left(0.12 \mathrm{~g}\right.$, yield of about $75 \%$ based on $\mathrm{H}_{5}$ hedp) were isolated as a pure phase, washed with distilled water, filtered, and then air-dried at room temperature. The $\mathrm{pH}$ of the solution was monitored before and after the reaction and determined to be ca. 1 . Elemental analysis: Calcd (\%) for $\mathrm{C}_{2} \mathrm{H}_{11} \mathrm{O}_{10} \mathrm{P}_{2} \mathrm{Eu}(\mathrm{MW}=409.01)$ : $\mathrm{C}$ 5.86, H 2.69; Found: C 5.01, H 2.75. Selected FT-IR (KBr pellets) and Raman main bands (inside the parenthesis in italic) (in $\mathrm{cm}^{-1}$ ): $v$ $(\mathrm{O}-\mathrm{H}$ water, $\mathrm{CO}-\mathrm{H}, \mathrm{PO}-\mathrm{H})=3521 \mathrm{~s} / \mathrm{sh}, 3443 \mathrm{~s} / \mathrm{br}, 3374 \mathrm{~s} / \mathrm{sh}(3423$ $w, 3352 w), \delta(\mathrm{O}-\mathrm{H}$, water $)=1629 \mathrm{~m} / \mathrm{br}, v(\mathrm{C}-\mathrm{O})=1152$ vs $(1147$ vs/sh, 1135 vs $), v_{\text {asym }}\left(\mathrm{P}-\mathrm{O}_{\text {coord }}\right)=1090$ vs, 1052 vs $(1087$ vs, 1076 $s / s h), v_{\text {sym }}\left(\mathrm{P}-\mathrm{O}_{\text {coord }}\right)=984$ vs $(991 v s)$ and $v_{\text {sym }}(\mathrm{P}-\mathrm{OH})=921 \mathrm{~s}(921$ s). TGA data (weight losses in \%) and DTG peaks (in italics inside the parentheses): $26-160{ }^{\circ} \mathrm{C}-15.8 \%\left(134{ }^{\circ} \mathrm{C}\right), 160-394{ }^{\circ} \mathrm{C}-12.1 \%$, and $394-700{ }^{\circ} \mathrm{C}-2.1 \%$.

Layered $\mathbf{N a}_{0.9}\left[\mathbf{N d}_{0.9} \mathbf{G e}_{0.10}(\right.$ Hhedp$\left.)\left(\mathrm{H}_{2} \mathrm{O}\right)_{2}\right](\mathbf{2 b})$. A mixture of 0.240 $\mathrm{g}$ of $\mathrm{Na}_{4}$ Hhedp $(0.97 \mathrm{mmol}), 0.170 \mathrm{~g}$ of $\mathrm{NdCl}_{3} \cdot 6 \mathrm{H}_{2} \mathrm{O}(0.47 \mathrm{mmol})$, $0.100 \mathrm{~g}$ of $\mathrm{GeO}_{2}(0.96 \mathrm{mmol})$, and $0.080 \mathrm{~g}$ of $\mathrm{C}_{8} \mathrm{H}_{6} \mathrm{O}_{4}(0.48 \mathrm{mmol})$ in ca. $20 \mathrm{~g}$ of distilled water was stirred thoroughly to homogeneity at ambient temperature for $1 \mathrm{~h}$. The reaction proceeded at $150{ }^{\circ} \mathrm{C}$ under autogenous pressure and hydrothermal static conditions for 5 days. Single crystals of $\mathbf{2} \mathbf{b}$ were isolated as a minor phase mixed with $\mathbf{1 d}$ and a white crystalline material.

Layered $\left[\mathbf{Y}\left(\mathbf{H}_{2}\right.\right.$ hedp $\left.)\left(\mathbf{H}_{2} \mathbf{O}\right)\right] \cdot 3 \mathbf{H}_{2} \mathbf{O}(\mathbf{3 a})$. A mixture of $0.100 \mathrm{~g}$ of $\mathrm{Na}_{4} \mathrm{Hhedp}(0.40 \mathrm{mmol}), 0.200 \mathrm{~g}$ of $\mathrm{YCl}_{3} \cdot 6 \mathrm{H}_{2} \mathrm{O}(0.66 \mathrm{mmol}), 0.170 \mathrm{~g}$ of $\mathrm{GeO}_{2}(1.62 \mathrm{mmol})$, and $0.160 \mathrm{~g}$ of $\mathrm{H}_{5}$ hedp $(0.78 \mathrm{mmol})$ in ca. $18 \mathrm{~g}$ of distilled water was stirred thoroughly at ambient temperature for half an hour. The reaction mixture was then transferred to a reaction vessel, which was placed inside an oven at $150{ }^{\circ} \mathrm{C}$. The reaction, under autogenous pressure and static conditions, proceeded for 3 days, leading to the isolation of single crystals of $\mathbf{3 a}$ as a pure phase $(0.22 \mathrm{~g}$, yield of ca. $91 \%$ based on $\mathrm{YCl}_{3} 6 \mathrm{H}_{2} \mathrm{O}$ ). The material was washed with distilled water, filtered, and then air-dried at room temperature. The $\mathrm{pH}$ of the solution was monitored before and after the reaction and determined to be ca. 1. Elemental analysis: Calcd (\%) for $\mathrm{C}_{2} \mathrm{H}_{13} \mathrm{O}_{11} \mathrm{P}_{2} \mathrm{Y}$ $(\mathrm{MW}=363.97)$ : C 6.59, H 3.57; Found: C 5.77, H 3.76. Selected FT-IR (KBr pellets) and Raman main bands (inside the parenthesis in italic) $\left(\right.$ in $\left.\mathrm{cm}^{-1}\right): v(\mathrm{O}-\mathrm{H}$ water, $\mathrm{CO}-\mathrm{H}, \mathrm{PO}-\mathrm{H})=3444 \mathrm{vs} / \mathrm{br}(3383$ $w / b r), \delta(\mathrm{O}-\mathrm{H}$, water $)=1641 \mathrm{~m} / \mathrm{br}, v(\mathrm{C}-\mathrm{O})=(1150 v s / s h, 1129 v s)$, $v_{\text {asym }}\left(\mathrm{P}-\mathrm{O}_{\text {coord }}\right)=1111 \mathrm{vs} / \mathrm{br}(1098 v s, 1080 \mathrm{~s} / \mathrm{sh}), v_{\text {sym }}\left(\mathrm{P}-\mathrm{O}_{\text {coord }}\right)=$ 1011 , vs/br $(993 v s)$ and $v_{\mathrm{sym}}(\mathrm{P}-\mathrm{OH})=960 \mathrm{~s} / \mathrm{br}(941 s)$. TGA data (weight losses in \%) and DTG peaks (in italics inside the parentheses): $26-207{ }^{\circ} \mathrm{C}-14.6 \%\left(88,97\right.$, and $\left.160^{\circ} \mathrm{C}\right)$, and $207-600{ }^{\circ} \mathrm{C}$ $-9.3 \%\left(239^{\circ} \mathrm{C}\right)$.

Layered $\left[\mathbf{T b}\left(\mathrm{H}_{2}\right.\right.$ hedp $\left.)\left(\mathrm{H}_{2} \mathrm{O}\right)\right] \cdot \mathbf{3} \mathbf{H}_{2} \mathrm{O}(3 \mathrm{~b})$. This material was prepared using an identical procedure to that described for 3a using 0.240 $\mathrm{g}$ of $\mathrm{TbCl}_{3} \cdot 6 \mathrm{H}_{2} \mathrm{O}$ replacing $\mathrm{YCl}_{3} \cdot 6 \mathrm{H}_{2} \mathrm{O}(0.270 \mathrm{~g}$ product, ca. $96 \%$ yield based on $\left.\mathrm{TbCl}_{3} \cdot 6 \mathrm{H}_{2} \mathrm{O}\right)$. Elemental analysis: Calcd (\%) for $\mathrm{C}_{2} \mathrm{H}_{13} \mathrm{O}_{11} \mathrm{P}_{2-}$ $\mathrm{Tb}(\mathrm{MW}=433.99)$ : C 5.53, H 2.99, Found: C 4.82, H 3.03. Selected FT-IR ( $\mathrm{KBr}$ pellets) and Raman main bands (inside the parenthesis in italic) (in $\left.\mathrm{cm}^{-1}\right): v(\mathrm{O}-\mathrm{H}$ water, $\mathrm{CO}-\mathrm{H}, \mathrm{PO}-\mathrm{H})=3486 \mathrm{vs} / \mathrm{br}(3400$ $w / b r, 3340 w / b r), \delta(\mathrm{O}-\mathrm{H}$, water $)=1637 \mathrm{~s}, v(\mathrm{C}-\mathrm{O})=1184,1147 \mathrm{vs}$ $(1145 v s / s h, 1136 v s), v_{\text {asym }}\left(\mathrm{P}-\mathrm{O}_{\text {coord }}\right)=1123$ vs $(1086 v s, 1075 \mathrm{~s} / \mathrm{sh})$, $v_{\text {sym }}\left(\mathrm{P}-\mathrm{O}_{\text {coord }}\right)=1047$ vs $(990 v s)$ and $v_{\text {sym }}(\mathrm{P}-\mathrm{OH})=926 \mathrm{~s} / \mathrm{sh}(924$ $s$ ). TGA data (weight losses in \%) and DTG peaks (in italics inside the parentheses): $26-196{ }^{\circ} \mathrm{C}-11.8 \%\left(85,104\right.$, and $\left.160^{\circ} \mathrm{C}\right)$, and $196-$ $700{ }^{\circ} \mathrm{C}-7.9 \%\left(226^{\circ} \mathrm{C}\right)$.

Layered [Yb( $\mathbf{H}_{2}$ hedp)] $\left(\mathrm{H}_{2} \mathrm{O}\right)$ (4). A mixture of $0.100 \mathrm{~g}$ of $\mathrm{Na}_{4}$ Hhedp $(0.40 \mathrm{mmol}), 0.300 \mathrm{~g}$ of $\mathrm{YbCl}_{3} \cdot 6 \mathrm{H}_{2} \mathrm{O}(0.77 \mathrm{mmol})$, and $0.080 \mathrm{~g}$ of $\mathrm{H}_{5}$ hedp $(0.39 \mathrm{mmol})$ in ca. $8 \mathrm{~g}$ of distilled water was stirred thoroughly at ambient temperature for half an hour. The hydrothermal reaction was carried out at $150{ }^{\circ} \mathrm{C}$, under autogenous pressure and static conditions, over a period of 3 days. Single crystals of $\mathbf{4}$ were isolated as a pure phase $\left(0.27 \mathrm{~g}\right.$, yield of about $88 \%$ based on $\left.\mathrm{YbCl}_{3} \cdot 6 \mathrm{H}_{2} \mathrm{O}\right)$, which were washed with distilled water, filtered, and then air-dried at room temperature. The $\mathrm{pH}$ of the solution was monitored before and after the reaction and determined to be ca. 1. Elemental analysis: Calcd (\%) for $\mathrm{C}_{2} \mathrm{H}_{7} \mathrm{O}_{8} \mathrm{P}_{2} \mathrm{Yb}(\mathrm{MW}=394.06)$ : C 6.09, $\mathrm{H}$ 1.77; Found: C 5.13, $\mathrm{H}$ 1.85. Selected FT-IR ( $\mathrm{KBr}$ pellets) and Raman main bands (inside the parenthesis in italic) $\left(\right.$ in $\left.\mathrm{cm}^{-1}\right): v(\mathrm{O}-\mathrm{H}$ water, $\mathrm{CO}-\mathrm{H}, \mathrm{PO}-\mathrm{H})=$ $3544 \mathrm{~s} / \mathrm{sh}, 3425 \mathrm{~s} / \mathrm{br}, \delta(\mathrm{O}-\mathrm{H}$, water $)=1647 \mathrm{~m} / \mathrm{br}, v(\mathrm{C}-\mathrm{O})=1174$ vs, 1147 vs, 1124 vs $(1155 v s), v_{\text {asym }}\left(\mathrm{P}-\mathrm{O}_{\text {coord }}\right)=1073 \mathrm{vs} / \mathrm{sh}, 1047 \mathrm{vs}$ $(1061 v s), v_{\text {sym }}\left(\mathrm{P}-\mathrm{O}_{\text {coord }}\right)=986$ vs $(988 v s)$ and $v_{\text {sym }}(\mathrm{P}-\mathrm{OH})=938 \mathrm{~s}$. TGA data (weight losses in \%) and DTG peaks (in italics inside the parentheses): $22-310{ }^{\circ} \mathrm{C}-4.2 \%$, and $310-450{ }^{\circ} \mathrm{C}-3.3 \%\left(360^{\circ} \mathrm{C}\right)$.

Dehydration-Rehydration Experiments. To effectively compare the photophysical (for 1e) and structural properties (for 1b) of the hydrated and dehydrated forms of the frameworks, these materials were calcined and kept under conditions that avoid partial or total rehydration.

For 1e, the sample was pressed into two identical pellets under the same conditions; the two samples were transferred to clean glass containers labeled as "dehydrated" and "rehydrated" and then calcined at $300{ }^{\circ} \mathrm{C}$ in open air for $4 \mathrm{~h}$ yielding 1e-dehyh. The "dehydrated" vial was firmly sealed with a hermetic lid when the oven was cooled to $100{ }^{\circ} \mathrm{C}$ and stored in a dry desiccator to prevent reabsorption of water. The "rehydrated" vial was moved into a humid environment where it stayed for 5 days to ensure a full rehydration of the material. The photoluminescent measurements for 1e, 1e-dehyd, and the rehydrated materials have been performed under the same conditions and on the same day.

For $\mathbf{1 b}$, the as-synthesized material was ground into a fine powder and heated at $300{ }^{\circ} \mathrm{C}$ in open air for $4 \mathrm{~h}$ to get the water-free product. The dehydrated phase was immediately sealed inside a rotor to perform the solid-state NMR experiments (see below). This water-free phase was then transferred to a clean glass vial and placed inside a humid environment where it stayed for 5 days to ensure full rehydration. The obtained rehydrated sample was then used for further solid-state NMR experiments.

General Characterization. FT-IR spectra were collected from $\mathrm{KBr}$ pellets (Aldrich 99\%+, FT-IR grade) on a Mattson 7000 FT-IR spectrometer. FT-Raman spectra were taken on a Bruker RFS 100 with a Nd:YAG coherent laser $(\lambda=1064 \mathrm{~nm})$. Elemental analyses for $\mathrm{C}$ and $\mathrm{H}$ were performed with a CHNS-932 Elemental analyzer in the Microanalysis Laboratory of the University of Aveiro, Department of Chemistry. TGAs were carried out using a Shimadzu TGA 50 with a heating rate of $5{ }^{\circ} \mathrm{C} / \mathrm{min}$ in air. Scanning electron microscopy (SEM) and energy dispersive analysis of X-rays spectroscopy (EDS) were performed using a Hitachi S-4100 field emission gun tungsten filament instrument working at $25 \mathrm{kV}$.

Photoluminescence Spectroscopy. Spectra were recorded at room temperature with a modular double grating excitation spectrofluorimeter with a TRIAX 320 emission monochromator (Fluorolog-3, Jobin Yvon- 
Spex) coupled to a R928 Hamamatsu photomultiplier, using the front face acquisition mode. The excitation source was a $450 \mathrm{~W}$ Xe arc lamp. The emission spectra were corrected for detection and optical spectral response of the spectrofluorimeter, and the excitation spectra were corrected for the spectral distribution of the lamp intensity using a photodiode reference detector. The lifetime measurements were acquired with the setup described for the luminescence spectra using a pulsed $\mathrm{Xe}-\mathrm{Hg}$ lamp (6 $\mu$ s pulse at half width and $20-30 \mu$ s tail).

Solid-State NMR Spectroscopy. ${ }^{31} \mathrm{P}$ and ${ }^{23} \mathrm{Na}$ NMR spectra were recorded on a Bruker Avance 400 (9.4 T) WB spectrometer (DSX model) at, respectively, 161.9 and $105.3 \mathrm{MHz}$, using a $4 \mathrm{~mm}$ BL CPMAS VTN double-bearing probe. ${ }^{23} \mathrm{Na}$ and ${ }^{31} \mathrm{P}$ chemical shifts are quoted in ppm from, respectively, aqueous $1 \mathrm{M} \mathrm{NaCl}$ and $85 \% \mathrm{H}_{3-}$ $\mathrm{PO}_{4}$.

For the ${ }^{31} \mathrm{P}$ CP-MAS measurements the Hartmann-Hahn "sideband" condition $v_{1}^{S}-v_{1}^{{ }^{1} H={ }_{R} v_{R}}(n= \pm 1, n= \pm 2)$ was carefully matched by calibrating the ${ }^{1} \mathrm{H}$ and the ${ }^{31} \mathrm{P} r f$ field strengths. ${ }^{23} \mathrm{Na}$ MAS NMR quantitative measurements were carried out using single-pulse excitation $\left(p_{\text {exc }}\right)$. Two-dimensional ${ }^{23} \mathrm{Na}$ triple-quantum (3Q) MAS NMR experiments were carried out with the z-filtered three-pulse sequence (two hard pulses, $p 1$ and $p 2$, and one final soft pulse, $p 3$ ). Data were sheared yielding an isotropic dimension, F1, free from anisotropic contributions. The SPAM method was used for sensitivity enhancement through multiple coherence selection during the conversion step. ${ }^{17}$ The following experimental parameters were used:

${ }^{1} \mathbf{H}-{ }^{31}$ P CP-MAS: $v_{1}^{13} c=55 \mathrm{kHz} ; v_{1}^{1}=$ ramped from 60 to $40 \mathrm{kHz}$; recycle delay $(\mathrm{RD})=5 \mathrm{~s}$; contact time $=2 \mathrm{~ms}$; number of scans (NS) $=16$; spinning rate $\left(v_{R}\right)=12 \mathrm{kHz}$.

${ }^{23}$ Na Single-Quantum MAS NMR: $p_{\mathrm{exc}}=0.6 \mu \mathrm{s}(\sim 70 \mathrm{kHz})$, equivalent to a $15^{\circ}$ flip angle measured on a $\mathrm{NaCl}$ solution; $\mathrm{RD}=1 \mathrm{~s}$; $\mathrm{NS}=2 \mathrm{k} ; v_{R}=14 \mathrm{kHz}$.

${ }^{23} \mathrm{Na}$ 3QMAS - Pulse Durations (rf Field Strength): $p 1=3.5 \mu \mathrm{s}$, $p 2=1.3 \mu \mathrm{s}\left(B_{I} \approx 150 \mathrm{kHz}\right)$ and $p 3=10.5 \mu \mathrm{s}\left(\mathrm{B}_{1} \approx 12 \mathrm{kHz}\right) ; t_{1}$ points $=32$; NS per $t_{1}$ point $=1680$; phase sensitive detection in $t_{1}$ : states acquisition; ${ }^{18} \mathrm{RD}=1 \mathrm{~s} ; v_{R}=14 \mathrm{kHz}$.

Single-Crystal X-Ray Diffraction. Suitable single-crystals were mounted on a glass fiber using FOMBLIN Y perfluoropolyether vacuum oil (LVAC 25/6) purchased from Aldrich. ${ }^{19}$ Data for compounds 1a, $\mathbf{1 b}, \mathbf{1 d}, \mathbf{1 e}$, and $\mathbf{1 g}$ were collected at $100 \mathrm{~K}$ (Unidade de Raios-X, RIAIDT, University of Santiago de Compostela, Spain) on a Bruker SMART 1000 CCD diffractometer (Mo K $\alpha$ graphite-monochromated radiation, $\lambda=0.7107 \AA$ ), controlled by the SMART software package. ${ }^{20}$ Images were processed using the SAINTPlus software package. ${ }^{21}$ Data for compound $\mathbf{1 f}$ was collected at $120 \mathrm{~K}$ on a Bruker-Nonius FR591 Kappa CCD 2000 diffractometer equipped with a rotating anode X-ray source $(\lambda=1.5418 \AA)$ and controlled by the COLLECT software package. ${ }^{22}$ Images for this structure were processed using the software packages Denzo and Scalepack. ${ }^{23}$ Data for compounds 1c, 1e-dehyd, 1h, 2a, 3, and $\mathbf{4}$ were collected on a Bruker X8 APEX-II diffractometer (Mo K $\alpha$ graphite-monochromated radiation, $\lambda=0.7107 \AA$ ) and controlled by the APEX2 software package. ${ }^{24}$ Images were processed using the SAINTPlus software package. ${ }^{21}$ Integrated data sets for all materials (except for 1e-dehyd) were corrected for absorption using the multiscan method implemented in SADABS. ${ }^{25}$

(17) Malicki, N.; Mafra, L.; Quoineaud, A.-A.; Rocha, J.; Thibault-Starzyka, F.; Fernandez, C. Solid State Nucl. Magn. Reson. 2005, 28, 13-21.

(18) States, D. J.; Haberkorn, R. A.; Ruben, D. J. J. Magn. Reson. 1982, 48, $286-292$.

(19) Kottke, T.; Stalke, D. J. Appl. Crystallogr. 1993, 26, 615-619.

(20) SMART Bruker Molecular Analysis Research Tool, v. 5.054; Bruker AXS: Madison, WI, 1998.

(21) SAINTPlus Data Reduction and Correction Program, v. 6.01; Bruker AXS: Madison, WI, 1998.

(22) Hooft, R. Collect: Data Collection Software; Nonius B. V.: Delft, The Netherlands, 1998.

(23) Otwinowski, Z.; Minor, W. In Methods in Enzymology Carter, C. W., Jr., Sweet, R. M., Eds.; Academic Press: New York, 1997; Vol. 276, p 307.

(24) APEX2 Data Collection Software, v. 2.1-RC13; Bruker AXS: Delft, The Netherlands, 2006.
The data collection of structure 1e-dehyd required special conditions. As-synthesized 1e was dehydrated over a period of $12 \mathrm{~h}$ at $300{ }^{\circ} \mathrm{C}$ and, at this temperature, the dehydrated compound was immediately immersed in FOMBLIN Y perfluoropolyether vacuum oil (LVAC 140/ 13) purchased from Aldrich. ${ }^{19} \mathrm{~A}$ judicious selection of the crystal used for data collection was performed using a Stemi 2000 stereomicroscope equipped with Carl Zeiss lenses, which allowed mounting on a Hampton Research CryoLoop. Even at the low temperature of 150(2) K, the selected crystal still diffracted very weakly at high angle. Moreover, a visual inspection of a set of centered reflections using RLATT ${ }^{26}$ revealed the presence of a rotational twin (non-merohedral). A full sphere of reflections was collected, and a partial data set was then deconvoluted using Bruker-Nonius CELL_NOW, ${ }^{27}$ producing a two-component twin, each accounting for ca. 1100 unique discrete reflections with 1479 unique reflections considered to be overlapped. The two domains were rotated by $180.0^{\circ}$ about the reciprocal axis $[1.000-0.003-0.003]$. The matrix used to relate the two orientations:

$$
\left(\begin{array}{lll}
1.001 & 0.004 & 0.310 \\
-0.006 & -1.000 & -0.001 \\
-0.007 & 0.000 & -1.001
\end{array}\right)
$$

was imported into SAINTPlus for data integration with the second twin component being identical to the first. Absorption corrections for 1edehyd were performed using TWINABS. ${ }^{28}$ The structure was solved with the sub-data set taken from the major domain (including overlapped reflections) and then refined against the two-component data set using the HKLF 5 format. Consequently, all reflections are treated as independent and no value of $R_{\text {int }}$ is provided (see Table 1). The batch scale factor (BASF) was refined to $0.43(1)$.

All structures were solved by the direct methods of SHELXS-97, ${ }^{29}$ which allowed the direct location of the majority of the heaviest atoms, with the remaining non-hydrogen atoms being located from difference Fourier maps calculated from successive full-matrix least-squares refinement cycles on $F^{2}$ using SHELXL-97. ${ }^{30}$ Non-hydrogen atoms of all materials (except for 1e-dehyd and $\mathbf{2 b}$ ) were successfully refined using anisotropic displacement parameters. In fact, besides crystallizing as a two-component twin, 1e-dehyd diffracted quite weakly at high angle, and a resolution cutoff at ca. $1.0 \AA[\sin (\theta) / \lambda=0.5]$ was applied to the data set to produce a reasonable structural model with feasible isotropic displacement parameters (anisotropic treatment led to nonpositive definite descriptions for all atoms).

The distinction between $\mathrm{Na}^{+}$cations and water molecules of crystallization, residing in the channels of family $\mathbf{1}$ compounds, was particularly challenging, especially because they have almost the same electron density. After a series of consecutive refinement cycles, the $\mathrm{Na}^{+}$cations were modeled over two distinct crystallographic positions, each carefully selected taking into consideration (i) $\mathrm{Na} \cdots \mathrm{O}$ distances with $\mathrm{O}$-atoms belonging to the frameworks and (ii) $\mathrm{Na} \cdots \mathrm{O}$ distances with (disordered) water molecules of crystallization lying in the channels. The occupancy of these two crystallographically independent $\mathrm{Na}^{+}$sites varies among the members of the series, but is closer to 0.6: 0.4 . This was further confirmed by solid-state NMR studies performed on the $\mathrm{La}^{3+}$-containing material $\mathbf{1 b}$ (see below).

Compound $\mathrm{Na}_{0.9}\left[\mathrm{Nd}_{0.9} \mathrm{Ge}_{0.10}(\right.$ Hhedp $\left.)\left(\mathrm{H}_{2} \mathrm{O}\right)_{2}\right]$ (2b) is structurally identical to $\mathbf{2 a}$, but the refinement led to unrealistic anisotropic

(25) Sheldrick, G. M. SADABS Bruker/Siemens Area Detector Absorption Correction Program, v.2.01; Bruker AXS: Madison, WI, 1998.

(26) RLATT: Reciprocal Lattice Viewer, v. 3.0; Bruker AXS: Madison, WI, 2000.

(27) Sheldrick, G. M. Bruker-Nonius CELL_NOW; Bruker AXS: Delft, The Netherlands, 2004.

(28) Sheldrick, G. M. TWINABS: An Empirical Absorption Correction Program, v. 1.05; Bruker AXS: Madison, WI, 2002.

(29) Sheldrick, G. M. SHELXS-97, Program for Crystal Structure Refinement; University of Göttingen: Göttingen, 1997.

(30) Sheldrick, G. M. SHELXS-97, Program for Crystal Structure Refinement; University of Göttingen: Göttingen, 1997. 
Table 1. Details on Crystal Data Collection and Structure Refinement

\begin{tabular}{|c|c|c|c|c|c|}
\hline & 1a & $1 b$ & 1c & $1 d$ & $1 e$ \\
\hline formula & $\mathrm{C}_{2} \mathrm{H}_{7.33} \mathrm{Na}_{2} \mathrm{O}_{7.67} \mathrm{P}_{2} \mathrm{Y}$ & \multirow{2}{*}{$\begin{array}{l}\mathrm{C}_{4} \mathrm{H}_{12} \mathrm{La}_{2} \mathrm{Na}_{4} \mathrm{O}_{17} \mathrm{P}_{4} \\
825.80\end{array}$} & $\mathrm{C}_{2} \mathrm{H}_{5.50} \mathrm{CeNa}_{2} \mathrm{O}_{8.50} \mathrm{P}_{2}$ & $\mathrm{C}_{4} \mathrm{H}_{12} \mathrm{Nd}_{2} \mathrm{Na}_{4} \mathrm{O}_{17} \mathrm{P}_{4}$ & $\mathrm{C}_{4} \mathrm{H}_{11} \mathrm{Eu}_{2} \mathrm{Na}_{4} \mathrm{O}_{16.5} \mathrm{P}_{4}$ \\
\hline formula weight & 350.92 & & 413.60 & 836.46 & 842.89 \\
\hline temperature/K & $100(2)$ & $100(2)$ & $175(2)$ & $100(2)$ & $100(2)$ \\
\hline crystal type & colorless plates & colorless prisms & colorless prisms & colorless prisms & colorless prisms \\
\hline crystal size $/ \mathrm{mm}$ & $0.19 \times 0.13 \times 0.05$ & \multirow{2}{*}{$\begin{array}{l}0.27 \times 0.14 \times 0.13 \\
\text { orthorhombic }\end{array}$} & $0.20 \times 0.18 \times 0.14$ & $0.24 \times 0.12 \times 0.10$ & $0.14 \times 0.12 \times 0.11$ \\
\hline crystal system & orthorhombic & & orthorhombic & orthorhombic & orthorhombic \\
\hline space group & Pnma & Pnma & Pnma & Pnma & Pnта \\
\hline$a / \AA$ & $10.498(2)$ & $10.755(2)$ & $10.6825(2)$ & $10.476(2)$ & $10.438(2)$ \\
\hline$b / \AA$ & $8.5000(17)$ & $8.8470(18)$ & $8.8219(2)$ & $8.7385(17)$ & $8.6510(17)$ \\
\hline$c / \AA ̊$ & $9.940(2)$ & $10.534(2)$ & $10.4567(2)$ & $10.543(2)$ & $10.398(2)$ \\
\hline$\alpha / \operatorname{deg}$ & 90 & 90 & 90 & 90 & 90 \\
\hline$\beta / \mathrm{deg}$ & 90 & 90 & 90 & 90 & 90 \\
\hline$\gamma / \mathrm{deg}$ & 90 & \multirow{2}{*}{$\begin{array}{l}90 \\
1002.3(4)\end{array}$} & 90 & 90 & 90 \\
\hline volume $/ \AA^{3}$ & $887.0(3)$ & & $985.44(3)$ & $965.1(3)$ & $938.9(3)$ \\
\hline$Z$ & 4 & 2 & 4 & 2 & 2 \\
\hline$\rho_{\text {calculated }} / \mathrm{g} \mathrm{cm}^{-3}$ & 2.628 & 2.736 & 2.788 & 2.878 & 2.981 \\
\hline$\mu / \mathrm{mm}^{-1}$ & 8.284 & 4.691 & 5.055 & 5.825 & 7.134 \\
\hline$\theta$ range/deg & $3.70-26.33$ & $3.55-27.93$ & $3.57-25.34$ & $3.60-25.34$ & $3.63-25.35$ \\
\hline index ranges & $-13 \leq h \leq 12$ & $-14 \leq h \leq 14$ & $-12 \leq h \leq 12$ & $-12 \leq h \leq 12$ & $-12 \leq h \leq 12$ \\
\hline & $-10 \leq k \leq 10$ & $-11 \leq k \leq 11$ & $-10 \leq k \leq 10$ & $-10 \leq k \leq 10$ & $-10 \leq k \leq 10$ \\
\hline & $-12 \leq l \leq 6$ & $-11 \leq l \leq 13$ & $-12 \leq l \leq 10$ & $-12 \leq l \leq 12$ & $-12 \leq l \leq 12$ \\
\hline collec. reflections & 3873 & 9947 & 28064 & 9053 & 6912 \\
\hline indep. reflections & 956 & 1274 & 965 & 948 & 917 \\
\hline & $\left(R_{\mathrm{int}}=0.0399\right)$ & $\left(R_{\mathrm{int}}=0.0415\right)$ & $\left(R_{\mathrm{int}}=0.0267\right)$ & $\left(R_{\text {int }}=0.0367\right)$ & $\left(R_{\mathrm{int}}=0.0376\right)$ \\
\hline final $R$ indices & $R 1=0.0402$ & $R 1=0.0282$ & $R 1=0.0223$ & $R 1=0.0175$ & $R 1=0.0198$ \\
\hline$[I>2 \sigma(I)]$ & $\mathrm{w} R 2=0.0941$ & $\mathrm{w} R 2=0.0780$ & $\mathrm{w} R 2=0.0526$ & $\mathrm{w} R 2=0.0431$ & $\mathrm{w} R 2=0.0475$ \\
\hline final $R$ indices & $R 1=0.0529$ & $R 1=0.0345$ & $R 1=0.0228$ & $R 1=0.0199$ & $R 1=0.0242$ \\
\hline (all data) & $\mathrm{w} R 2=0.1015$ & $\mathrm{w} R 2=0.0815$ & $\mathrm{w} R 2=0.0528$ & $\mathrm{w} R 2=0.0440$ & $\mathrm{w} R 2=0.0492$ \\
\hline $\begin{array}{l}\text { largest diff. peak and } \\
\text { hole } / \AA^{3}\end{array}$ & 0.947 and -1.121 & 0.706 and -1.729 & 0.566 and -0.903 & 0.477 and -0.899 & 0.662 and -0.784 \\
\hline CCDC No. & 602523 & 602524 & 644029 & 602525 & 602526 \\
\hline & 1e-dehyd & $1 f$ & $1 \mathrm{~g}$ & $1 \mathrm{~h}$ & $2 a$ \\
\hline formula & $\mathrm{C}_{2} \mathrm{H}_{3} \mathrm{EuNaO}_{7} \mathrm{P}_{2}$ & $\mathrm{C}_{2} \mathrm{H}_{5} \mathrm{GdNa}_{2} \mathrm{O}_{8} \mathrm{P}_{2}$ & $\mathrm{C}_{4} \mathrm{H}_{11} \mathrm{Na}_{4} \mathrm{O}_{16.5} \mathrm{P}_{4} \mathrm{~Tb}_{2}$ & $\mathrm{C}_{2} \mathrm{H}_{5} \mathrm{ErNa}_{2} \mathrm{O}_{8} \mathrm{P}_{2}$ & $\mathrm{C}_{2} \mathrm{H}_{11} \mathrm{EuO}_{10} \mathrm{P}_{2}$ \\
\hline formula weight & 375.93 & 422.23 & 356.81 & - & 409.01 \\
\hline temperature/K & $150(2)$ & $120(2)$ & $100(2)$ & $150(2)$ & $180(2)$ \\
\hline crystal type & colorless blocks & colorless prisms & colorless prisms & pink prisms & colorless prisms \\
\hline crystal size $/ \mathrm{mm}$ & $0.10 \times 0.05 \times 0.04$ & $0.03 \times 0.03 \times 0.02$ & $0.08 \times 0.05 \times 0.05$ & $0.16 \times 0.16 \times 0.12$ & $0.16 \times 0.10 \times 0.05$ \\
\hline crystal system & monoclinic & orthorhombic & orthorhombic & orthorhombic & orthorhombic \\
\hline space group & $P 2_{1} / c$ & Pnma & Pnma & Bravais Lattice $P$ & Pbca \\
\hline$a / \AA$ & $8.0636(19)$ & $10.4217(5)$ & $10.519(2)$ & $8.476(3)$ & $9.7235(2)$ \\
\hline$b / \AA$ & $9.7171(19)$ & $8.6462(4)$ & $8.6060(17)$ & $9.927(3)$ & $9.7323(2)$ \\
\hline$c / \AA ̊$ & $9.972(2)$ & $10.3000(5)$ & $9.999(2)$ & $10.456(5)$ & $20.4210(5)$ \\
\hline$\alpha / \operatorname{deg}$ & 90 & 90 & 90 & 90 & 90 \\
\hline$\beta / \mathrm{deg}$ & $100.972(8)$ & 90 & 90 & 90 & 90 \\
\hline$\gamma / \mathrm{deg}$ & 90 & 90 & 90 & 90 & 90 \\
\hline volume $/ \AA^{3}$ & $767.0(3)$ & $928.11(8)$ & $905.2(3)$ & $879.8(9)$ & $1932.48(7)$ \\
\hline$Z$ & 4 & 4 & 2 & - & 8 \\
\hline$\rho_{\text {calculated }} / \mathrm{g} \mathrm{cm}^{-3}$ & 3.255 & 3.022 & 3.144 & - & 2.812 \\
\hline$\mu / \mathrm{mm}^{-1}$ & 8.651 & 49.825 & 8.284 & - & 6.862 \\
\hline$\theta$ range $/ \mathrm{deg}$ & $2.57-20.81$ & $7.93-66.59$ & $3.68-27.24$ & - & $3.57-25.35$ \\
\hline index ranges & $-8 \leq h \leq 7$ & $0 \leq h \leq 12$ & $-13 \leq h \leq 13$ & - & $-11 \leq h \leq 11$ \\
\hline & $-9 \leq k \leq 9$ & $0 \leq k \leq 10$ & $-11 \leq k \leq 10$ & & $-11 \leq k \leq 11$ \\
\hline & $-0 \leq l \leq 9$ & $0 \leq l \leq 12$ & $-12 \leq 1 \leq 12$ & & $-23 \leq l \leq 23$ \\
\hline collec. reflections & 2218 & 10272 & 14294 & - & 30457 \\
\hline indep. reflections & 2218 & 880 & 1070 & - & 1743 \\
\hline & & $\left(R_{\text {int }}=0.0735\right)$ & $\left(R_{\mathrm{int}}=0.1158\right)$ & & $\left(R_{\mathrm{int}}=0.0250\right)$ \\
\hline final $R$ indices & $R 1=0.0816$ & $R 1=0.0387$ & $R 1=0.0377$ & - & $R 1=0.0168$ \\
\hline$[I>2 \sigma(I)]$ & $\mathrm{w} R 2=0.2385$ & $\mathrm{w} R 2=0.1073$ & $\mathrm{w} R 2=0.0689$ & & $\mathrm{w} R 2=0.0397$ \\
\hline final $R$ indices & $R 1=0.1007$ & $R 1=0.0390$ & $R 1=0.0660$ & - & $R 1=0.0240$ \\
\hline (all data) & $\mathrm{w} R 2=0.2603$ & $\mathrm{w} R 2=0.1075$ & $\mathrm{w} R 2=0.0791$ & - & $\mathrm{w} R 2=0.0438$ \\
\hline $\begin{array}{l}\text { largest diff. peak and } \\
\text { hole } / \mathrm{e}^{3}\end{array}$ & 6.415 and -8.186 & 1.010 and -1.026 & 2.409 and -1.758 & - & 0.777 and -0.768 \\
\hline CCDC No. & 644030 & 602527 & 602528 & - & 644031 \\
\hline & $2 \mathbf{b}$ & & $3 a$ & $3 b$ & 4 \\
\hline formula & $\mathrm{C}_{2} \mathrm{H}_{8} \mathrm{Ge}_{0.10} \mathrm{Na}_{0.90} \mathrm{~N}$ & ${ }_{0} \mathrm{O}_{9} \mathrm{P}_{2}$ & ${ }_{11} \mathrm{P}_{2} \mathrm{Y}$ & $\mathrm{C}_{2} \mathrm{H}_{13} \mathrm{O}_{11} \mathrm{P}_{2} \mathrm{~Tb}$ & $\mathrm{C}_{2} \mathrm{H}_{7} \mathrm{O}_{8} \mathrm{P}_{2} \mathrm{Yb}$ \\
\hline formula weight & 395.79 & 363. & & - & 394.06 \\
\hline temperature/K & $100(2)$ & 150 & & $150(2)$ & $150(2)$ \\
\hline crystal type & colorless prisms & colo & s plates & colorless plates & colorless plates \\
\hline crystal size/mm & $0.09 \times 0.05 \times 0.03$ & 0.24 & $0.08 \times 0.03$ & - & $0.18 \times 0.16 \times 0.10$ \\
\hline crystal system & orthorhombic & mon & inic & monoclinic & triclinic \\
\hline space group & $P b c a$ & $P 2_{1} /$ & & Bravais Lattice $P$ & $P \overline{1}$ \\
\hline$a / \AA$ & $9.774(5)$ & 11.6 & $3(2)$ & $11.216(17)$ & $5.3097(3)$ \\
\hline
\end{tabular}


Table 1. (Continued)

\begin{tabular}{|c|c|c|c|c|}
\hline & $2 \mathbf{b}$ & $3 a$ & $3 b$ & 4 \\
\hline$b / \AA ̊ ̊$ & $20.406(9)$ & $9.1515(2)$ & $9.191(14)$ & $6.7900(4$ \\
\hline$c / \AA ̊$ & $9.805(5)$ & $11.1093(2)$ & $11.654(17)$ & $12.0310(7)$ \\
\hline$\alpha / \mathrm{deg}$ & 90 & 90 & 90 & $80.490(2)$ \\
\hline$\beta / \mathrm{deg}$ & 90 & $111.372(1)$ & $111.58(3)$ & $81.694(2)$ \\
\hline$\gamma / \mathrm{deg}$ & 90 & 90 & 90 & $77.851(2)$ \\
\hline volume $/ \AA^{3}$ & $1955.8(16)$ & $1100.35(4)$ & $1117(3)$ & $415.49(4)$ \\
\hline$Z$ & 8 & 4 & - & 2 \\
\hline$\rho_{\text {calculated }} / \mathrm{g} \mathrm{cm}^{-3}$ & 2.688 & 2.197 & - & 3.150 \\
\hline$\mu / \mathrm{mm}^{-1}$ & 5.486 & 5.638 & - & 11.652 \\
\hline$\theta$ range/deg & $3.56-25.35$ & $3.70-25.35$ & - & $3.75-27.47$ \\
\hline \multirow[t]{3}{*}{ index ranges } & $0 \leq h \leq 11$ & $-13 \leq h \leq 14$ & - & $-6 \leq h \leq 6$ \\
\hline & $0 \leq k \leq 24$ & $-11 \leq k \leq 11$ & - & $-8 \leq k \leq 8$ \\
\hline & $0 \leq l \leq 11$ & $-13 \leq l \leq 13$ & - & $-15 \leq l \leq 15$ \\
\hline collec. reflections & 16220 & 23953 & - & 14656 \\
\hline indep. reflections & $1785\left(R_{\text {int }}=0.1260\right)$ & $1900\left(R_{\mathrm{int}}=0.0418\right)$ & - & $1808\left(R_{\mathrm{int}}=0.0231\right)$ \\
\hline final $R$ indices & $R 1=0.0457$ & $R 1=0.0195$ & - & $R 1=0.0146$ \\
\hline$[I>2 \sigma(I)]$ & $\mathrm{w} R 2=0.0925$ & $\mathrm{w} R 2=0.0444$ & & $\mathrm{w} R 2=0.0353$ \\
\hline final $R$ indices & $R 1=0.0904$ & $R 1=0.0256$ & - & $R 1=0.015$ \\
\hline (all data) & $\mathrm{w} R 2=0.0983$ & $\mathrm{w} R 2=0.0463$ & & $\mathrm{w} R 2=0.0356$ \\
\hline $\begin{array}{l}\text { largest diff. peak and } \\
\text { hole /e } \AA^{3}\end{array}$ & 1.468 and -1.872 & 0.390 and -0.384 & - & 0.838 and -0.894 \\
\hline CCDC No. & 644032 & 644033 & - & 644034 \\
\hline
\end{tabular}

displacement parameters for the vast majority of non-hydrogen atoms, in particular the central $\mathrm{Nd}^{3+}$ cation. Refinement considering partial substitution of the lanthanide center by $\mathrm{Ge}^{4+}$ accounted for all electron density, leading to the structural parameters collected in Table 1. The $\mathrm{Nd}^{3+}$ and $\mathrm{Ge}^{4+}$ were restrained to occupy the same crystallographic position (sharing identical anisotropic displacement parameters). Unrestrained refinement of the site occupancies led to a $\mathrm{Nd} / \mathrm{Ge}$ ratio of 9:1, and this occupancy was fixed during the last stages of the refinement. Consequently, to balance the crystal charge, some water molecules lying in the interlayer spaces are partially substituted by $\mathrm{Na}^{+}$ cations. Their position was located using a strategy identical to that described in the previous paragraph.

The methyl group hydrogen atoms were located at their idealized positions using either the HFIX 33 or the 137 instructions in SHELXL97. ${ }^{30}$ Hydrogen atoms associated with the $-\mathrm{OH}$ groups of the organic and water molecules (coordinated and uncoordinated) were markedly visible in the difference Fourier maps, and included in subsequent refinement stages with the $\mathrm{O}-\mathrm{H}$ and $\mathrm{H} \cdots \mathrm{H}$ distances restrained to 0.95 (1) and $1.45(1) \AA$, respectively (to ensure a chemically reasonable geometry for these molecules), and using a riding-motion approximation with an isotropic thermal displacement parameter fixed at 1.5 times $\mathrm{U}_{\mathrm{eq}}$ of the oxygen atom to which they are attached.

Information concerning the crystallographic data collection and structure refinement is summarized in Table 1. Crystallographic data (excluding structure factors) for the structures reported in this paper have been deposited with the Cambridge Crystallographic Data Centre (see deposition numbers in Table 1). Copies of the data may be obtained free of charge on application to CCDC, 12 Union Road, Cambridge CB22EZ,U.K.FAX: (+44)1223336033.E-mail: deposit@ccdc.cam.ac.uk.

Powder X-Ray Diffraction. Powder X-ray diffraction (PXRD) data were collected at ambient temperature on a X'Pert MPD Philips diffractometer ( $\mathrm{Cu} \mathrm{K} \alpha$ X-radiation, $\lambda=1.54060 \AA$ ), equipped with a $\mathrm{X}$ 'Celerator detector, a curved graphite-monochromated radiation and a flat-plate sample holder, in a Bragg-Brentano para-focusing optics configuration $(40 \mathrm{kV}, 50 \mathrm{~mA})$. Intensity data were collected in the continuous scanning mode in the range ca. $5 \leq 2 \theta^{\circ} \leq 50$. The variable temperature experiments performed on $\mathrm{Na}_{4}\left[\mathrm{Eu}_{2}(\text { hedp })_{2}\left(\mathrm{H}_{2} \mathrm{O}\right)_{2}\right] \cdot \mathrm{H}_{2} \mathrm{O}(\mathbf{1 e})$ were conducted on the same instrument using a high-temperature Antoon Parr HKL 16 chamber, controlled by a Antoon Parr 100 TCU unit. Intensity data were collected in the step mode $\left(0.02^{\circ}, 5 \mathrm{~s}\right.$ per step) in the range ca. $10 \leq 2 \theta^{\circ} \leq 35$.

\section{Results and Discussion}

Framework Rare-Earth Organic Materials. A series of novel porous rare-earth organic framework (REOF) materials, formulated as $\mathrm{Na}_{2}\left[\mathrm{Y}(\right.$ hedp $\left.)\left(\mathrm{H}_{2} \mathrm{O}\right)_{0.67}\right]$ (1a) and $\mathrm{Na}_{4}\left[\mathrm{Ln}_{2} \text { (hedp) }\right)_{2}-$ $\left.\left(\mathrm{H}_{2} \mathrm{O}\right)_{2}\right] \cdot n \mathrm{H}_{2} \mathrm{O}[\mathrm{Ln}=\mathrm{La}(\mathbf{1 b}), \mathrm{Ce}(\mathbf{1 c}), \mathrm{Nd}(\mathbf{1 d}), \mathrm{Eu}(\mathbf{1 e}), \mathrm{Gd}$ (1f), Tb (1g), and $\mathrm{Er}(\mathbf{1 h})]$ on the basis of single-crystal X-ray diffraction (Table 1) in tandem with thermogravimetry and solidstate NMR studies, have been isolated as highly crystalline phases (Figure S1 in Supporting Information) crystallizing in the orthorhombic high-symmetry space group Pnma. All of these materials are isostructural, and the structure details will be discussed only for $\mathrm{Na}_{4}\left[\mathrm{Eu}_{2}\left(\mathrm{H}_{2} \mathrm{O}\right)_{2}(\text { hedp })_{2}\right] \cdot \mathrm{H}_{2} \mathrm{O}$ (1e), a solid whose photoluminescence properties were studied in detail. The structure of dehydrated 1e, $\mathrm{Na}[\mathrm{Eu}($ hedp)] (1e-dehyd), was also determined by single-crystal X-ray diffraction. Dehydration reduces the overall symmetry from the orthorhombic Pnma system to the monoclinic $P 2_{1} / c$ system. Both in the hydrated and dehydrated forms, the crystallographic unique $\mathrm{Eu}^{3+}$ center is coordinated by eight oxygen atoms. In 1e, the lanthanide coordination sphere encompasses seven oxygen atoms from four crystallographically related organic (hedp ${ }^{5-}$ ) ligands, with the remaining oxygen belonging to one water molecule. The $\mathrm{Eu}-\mathrm{O}$ distances and $\mathrm{O}-\mathrm{Eu}-\mathrm{O}$ angles are, respectively, in the 2.300(3) $-2.698(4) \AA$ and $66.97(10)-147.48(12)^{\circ}$ ranges (Table 2), describing a distorted monocapped trigonal coordination geometry (Figures 1a and S2a in the Supporting Information). The hedp ${ }^{5-}$ anion acts as a heptadentate ligand (Figure 1): it binds to one $\mathrm{Eu}^{3+}$ cation via a bidentate interaction through the two phosphonate groups; the chelation to a neighbor $\mathrm{Eu}^{3+}$ involves the two phosphonate groups plus the central deprotonated hydroxyl group; additionally, two bridging monodentate interactions with other two symmetry-generated $\mathrm{Eu}^{3+}$ ions complete the coordination sphere. Although in the dehydrated form (1edehyd) the Eu-coordinated water molecule of 1e is removed, the eight-coordination environment remains as result of the high flexibility of the organic PBU. In 1e-dehyd all oxygen atoms composing the coordination sphere belong to hedp ${ }^{5-}$ ligands [Eu-O distances and $\mathrm{O}-\mathrm{Eu}-\mathrm{O}$ angles found in the 2.301(13)2.789(15) Å and 57.7(5)-159.3(5) ${ }^{\circ}$ ranges, respectively, Table 
Table 2. Selected Bond Lengths $(\AA)$ and Angles (deg) for the $\mathrm{Eu}^{3+}$ Coordination Environments Present in $\mathrm{Na}_{4}\left[\mathrm{Eu}_{2}(\text { hedp })_{2}\left(\mathrm{H}_{2} \mathrm{O}\right)_{2}\right] \cdot \mathrm{H}_{2} \mathrm{O}\left(\right.$ (1e) and $\mathrm{Na}\left[\mathrm{Eu}\left(\right.\right.$ hedp)] (1e-dehyd) ${ }^{a}$

\begin{tabular}{|c|c|c|c|}
\hline \multicolumn{4}{|c|}{ 1e } \\
\hline $\mathrm{Eu}(1)-\mathrm{O}(1)$ & $2.430(3)$ & $\mathrm{O}(1)-\mathrm{Eu}(1)-\mathrm{O}(3)^{\mathrm{v}}$ & $138.13(12)$ \\
\hline $\mathrm{Eu}(1)-\mathrm{O}(1)^{\mathrm{i}}$ & $2.430(3)$ & $\mathrm{O}(1)-\mathrm{Eu}(1)-\mathrm{O}(4)$ & $66.97(10)$ \\
\hline $\mathrm{Eu}(1)-\mathrm{O}(2)^{\mathrm{ii}}$ & $2.371(3)$ & $\mathrm{O}(1)-\mathrm{Eu}(1)-\mathrm{O}(1 \mathrm{~W})$ & $140.66(8)$ \\
\hline $\mathrm{Eu}(1)-\mathrm{O}(2)^{\mathrm{iii}}$ & $2.371(3)$ & $\mathrm{O}(2)^{\mathrm{ii}}-\mathrm{Eu}(1)-\mathrm{O}(2)^{\mathrm{iii}}$ & $74.66(14)$ \\
\hline $\mathrm{Eu}(1)-\mathrm{O}(3)^{\mathrm{iv}}$ & $2.300(3)$ & $\mathrm{O}(2)^{\mathrm{ii}}-\mathrm{Eu}(1)-\mathrm{O}(3)^{\mathrm{iv}}$ & $147.48(12)$ \\
\hline $\mathrm{Eu}(1)-\mathrm{O}(3)^{\mathrm{v}}$ & $2.300(3)$ & $\mathrm{O}(2)^{\mathrm{ii}}-\mathrm{Eu}(1)-\mathrm{O}(3)^{\mathrm{v}}$ & $89.05(13)$ \\
\hline $\mathrm{Eu}(1)-\mathrm{O}(4)$ & $2.698(4)$ & $\mathrm{O}(2)^{\mathrm{ii}}-\mathrm{Eu}(1)-\mathrm{O}(4)$ & $137.90(8)$ \\
\hline $\mathrm{Eu}(1)-\mathrm{O}(1 \mathrm{~W})$ & $2.496(5)$ & $\begin{array}{l}\mathrm{O}(2)^{\mathrm{ii}}-\mathrm{Eu}(1)-\mathrm{O}(1 \mathrm{~W}) \\
\mathrm{O}\left(3^{\mathrm{iv}}-\mathrm{Eu}(1)-\mathrm{O}(3)^{\mathrm{v}}\right.\end{array}$ & $\begin{array}{l}73.01(12) \\
90.3(2)\end{array}$ \\
\hline $\mathrm{O}(1)-\mathrm{Eu}(1)-\mathrm{O}(1)^{\mathrm{i}}$ & $74.85(17)$ & $\mathrm{O}(3)^{\mathrm{iv}}-\mathrm{Eu}(1)-\mathrm{O}(4)$ & $71.72(11)$ \\
\hline $\mathrm{O}(1)-\mathrm{Eu}(1)-\mathrm{O}(2)^{\mathrm{ii}}$ & $117.47(11)$ & $\mathrm{O}(3)^{\mathrm{iv}}-\mathrm{Eu}(1)-\mathrm{O}(1 \mathrm{~W})$ & $75.39(12)$ \\
\hline $\mathrm{O}(1)-\mathrm{Eu}(1)-\mathrm{O}(2)^{\mathrm{iii}}$ & $73.99(10)$ & $\mathrm{O}(4)-\mathrm{Eu}(1)-\mathrm{O}(1 \mathrm{~W})$ & $132.63(15)$ \\
\hline $\mathrm{O}(1)-\mathrm{Eu}(1)-\mathrm{O}(3)^{\mathrm{iv}}$ & $83.28(13)$ & & \\
\hline \multicolumn{4}{|c|}{ 1e-dehyd } \\
\hline $\mathrm{Eu}(1)-\mathrm{O}(1)$ & $2.333(15)$ & $\mathrm{O}(2)^{\mathrm{vi}}-\mathrm{Eu}(1)-\mathrm{O}(5)^{\mathrm{viii}}$ & $94.1(5)$ \\
\hline $\mathrm{Eu}(1)-\mathrm{O}(2)^{\mathrm{vi}}$ & $2.301(13)$ & $\mathrm{O}(2)^{\mathrm{vi}}-\mathrm{Eu}(1)-\mathrm{O}(6)^{\mathrm{vii}}$ & $140.8(5)$ \\
\hline $\mathrm{Eu}(1)-\mathrm{O}(3)^{\mathrm{vii}}$ & $2.295(16)$ & $\mathrm{O}(2)^{\mathrm{vi}}-\mathrm{Eu}(1)-\mathrm{O}(7)^{\mathrm{viii}}$ & $77.0(5)$ \\
\hline $\mathrm{Eu}(1)-\mathrm{O}(4)$ & $2.789(15)$ & $\mathrm{O}(3)^{\mathrm{vii}}-\mathrm{Eu}(1)-\mathrm{O}(4)$ & $136.3(5)$ \\
\hline $\mathrm{Eu}(1)-\mathrm{O}(5)$ & $2.396(14)$ & $\mathrm{O}(3)^{\mathrm{vii}}-\mathrm{Eu}(1)-\mathrm{O}(5)$ & 127.1(6) \\
\hline $\mathrm{Eu}(1)-\mathrm{O}(5)^{\mathrm{viii}}$ & $2.614(14)$ & $\mathrm{O}(3)^{\mathrm{vii}}-\mathrm{Eu}(1)-\mathrm{O}(5)^{\mathrm{viii}}$ & $149.0(5)$ \\
\hline $\mathrm{Eu}(1)-\mathrm{O}(6)^{\mathrm{vii}}$ & $2.404(14)$ & $\mathrm{O}(3)^{\mathrm{vii}}-\mathrm{Eu}(1)-\mathrm{O}(6)^{\mathrm{vii}}$ & $74.0(5)$ \\
\hline \multirow[t]{2}{*}{$\mathrm{Eu}(1)-\mathrm{O}(7)^{\mathrm{viii}}$} & $2.483(15)$ & $\mathrm{O}(3)^{\mathrm{vii}}-\mathrm{Eu}(1)-\mathrm{O}(7)^{\mathrm{viii}}$ & $91.6(5)$ \\
\hline & & $\mathrm{O}(4)-\mathrm{Eu}(1)-\mathrm{O}(5)$ & $64.3(5)$ \\
\hline $\mathrm{O}(1)-\mathrm{Eu}(1)-\mathrm{O}(2)^{\mathrm{vi}}$ & $86.2(5)$ & $\mathrm{O}(4)-\mathrm{Eu}(1)-\mathrm{O}(5)^{\mathrm{viii}}$ & $71.0(4)$ \\
\hline $\mathrm{O}(1)-\mathrm{Eu}(1)-\mathrm{O}(3)^{\mathrm{vii}}$ & $73.6(5)$ & $\mathrm{O}(4)-\mathrm{Eu}(1)-\mathrm{O}(6)^{\mathrm{vii}}$ & $139.5(4)$ \\
\hline $\mathrm{O}(1)-\mathrm{Eu}(1)-\mathrm{O}(4)$ & $66.9(5)$ & $\mathrm{O}(4)-\mathrm{Eu}(1)-\mathrm{O}(7)^{\mathrm{viii}}$ & $120.4(5)$ \\
\hline $\mathrm{O}(1)-\mathrm{Eu}(1)-\mathrm{O}(5)$ & $80.9(5)$ & $\mathrm{O}(5)-\mathrm{Eu}(1)-\mathrm{O}(5)^{\mathrm{viii}}$ & $73.1(6)$ \\
\hline $\mathrm{O}(1)-\mathrm{Eu}(1)-\mathrm{O}(5)^{\mathrm{viii}}$ & $136.9(5)$ & $\mathrm{O}(5)-\mathrm{Eu}(1)-\mathrm{O}(6)^{\mathrm{vii}}$ & $75.7(4)$ \\
\hline $\mathrm{O}(1)-\mathrm{Eu}(1)-\mathrm{O}(6)^{\mathrm{vii}}$ & $114.2(5)$ & $\mathrm{O}(5)-\mathrm{Eu}(1)-\mathrm{O}(7)^{\mathrm{viii}}$ & $119.8(5)$ \\
\hline $\mathrm{O}(1)-\mathrm{Eu}(1)-\mathrm{O}(7)^{\mathrm{viii}}$ & $159.3(5)$ & $\mathrm{O}(5)^{\mathrm{viii}}-\mathrm{Eu}(1)-\mathrm{O}(6)^{\mathrm{vii}}$ & $92.1(5)$ \\
\hline $\mathrm{O}(2)^{\mathrm{vi}}-\mathrm{Eu}(1)-\mathrm{O}(3)^{\mathrm{vii}}$ & $81.1(5)$ & $\mathrm{O}(5)^{\mathrm{viii}}-\mathrm{Eu}(1)-\mathrm{O}(7)^{\mathrm{viii}}$ & $57.7(5)$ \\
\hline $\mathrm{O}(2)^{\mathrm{vi}}-\mathrm{Eu}(1)-\mathrm{O}(4)$ & $78.5(5)$ & $\mathrm{O}(6)^{\mathrm{vii}}-\mathrm{Eu}(1)-\mathrm{O}(7)^{\mathrm{viii}}$ & $73.9(5)$ \\
\hline $\mathrm{O}(2)^{\mathrm{vi}}-\mathrm{Eu}(1)-\mathrm{O}(5)$ & $142.8(5)$ & & \\
\hline
\end{tabular}

${ }^{a}$ Symmetry transformations used to generate equivalent atoms: (i) $x$, $-y+1 / 2, z$; (ii) $x+1 / 2,-y+1 / 2,-z+1 / 2$; (iii) $x+1 / 2, y,-z+1 / 2$; (iv) $-x+2,-y$, $-z$; (v) $-x+2, y+1 / 2,-z$; (vi) $2-x, 2-y, 1-z$; (vii) $x, 3 / 2-y, 1 / 2+z$; (viii) $1-x$, $2-y, 1-z$.

2]. In this compound, the position of the water molecule is occupied by a phosphonate group (see Figure 1), and as a result, the monocaped trigonal coordination geometry of $\mathrm{Eu}^{3+}$ becomes more distorted (Figures $1 \mathrm{~b}$ and $\mathrm{S} 2 \mathrm{~b}$ in the Supporting Information). Besides these small differences, the connectivity of the hedp ${ }^{5-}$ ligand is similar in the two crystalline forms, being connected to four symmetry-related $\mathrm{Eu}^{3+}$ centers (Scheme S1 in the Supporting Information).

The structure of 1e contains a one-dimensional inorganicorganic chain, built up of $\left\{\mathrm{Eu}(\mathrm{hedp})\left(\mathrm{H}_{2} \mathrm{O}\right)\right\}$ fragments (secondary building units, SBUs) linked together in a zigzag-type fashion along the [010] direction of the unit cell and imposing an intermetallic Eu $\cdots$ Eu distance of 5.8127(8) ^ (Figure 2). Adjacent chains are interconnected via shared oxygen atoms $[\mathrm{O}(2)]$ of the phosphonate groups, originating an anionic porous rare-earth organic framework, with a two-dimensional system of channels running along the [100] and [010] crystallographic directions (Figure 2 and S3 in the Supporting Information). Whereas the channels parallel to the $b$-axis are defined by eightmembered rings formed by four $\left\{\mathrm{EuO}_{8}\right\}$ polyhedra and four phosphonate groups (average cross-section of $3.6 \times 1.5 \AA^{2}$, based on van der Waals radii), those parallel to the $a$-axis are undulated and composed of smaller six-membered rings (with two $\left\{\mathrm{EuO}_{8}\right\}$ polyhedra and four phosphonate groups, average
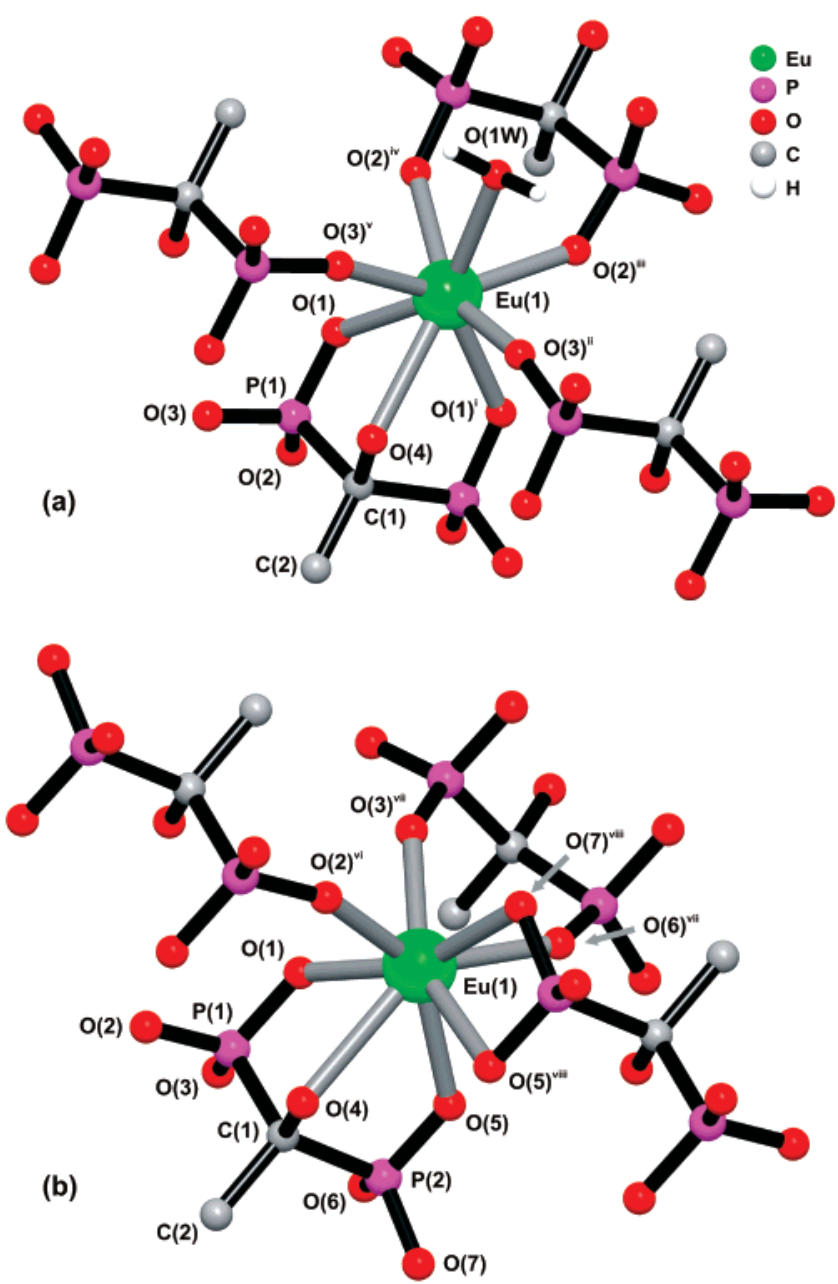

Figure 1. Coordination environments of the $\mathrm{Eu}^{3+}$ ions (gray colored bonds) in (a) $\mathrm{Na}_{4}\left[\mathrm{Eu}_{2}(\text { hedp })_{2}\left(\mathrm{H}_{2} \mathrm{O}\right)_{2}\right] \cdot \mathrm{H}_{2} \mathrm{O}$ (1e), and (b) $\mathrm{Na}[\mathrm{Eu}$ (hedp)] (1edehyd), showing the labeling scheme of all atoms belonging to respective asymmetric units and those composing the first coordination sphere. The hedp ${ }^{5-}$ hydrogen atoms were omitted for clarity. Symmetry transformations used to generate equivalent atoms: (i) $x,-y+1 / 2, z$; (ii) $x+1 / 2$, $-y+1 / 2,-z+1 / 2$; (iii) $x+1 / 2, y,-z+1 / 2$; (iv) $-x+2,-y,-z$; (v) $-x+2$, $y+1 / 2,-z$; (vi) $2-x, 2-y, 1-z$; (vii) $x, 3 / 2-y, 1 / 2+z$; (viii) $1-x, 2-y$, $1-z$

cross-section of $2.7 \times 0.8 \AA^{2}$ ) (Figure S3 in the Supporting Information).

As in microporous zeolites, this family of rare-earth organic materials contains charge-balancing $\mathrm{Na}^{+}$ions in the channels (not shown). Their presence and disordered nature was further confirmed by solid-state NMR (see below). Also in the channels, there is a partially-occupied water molecule $[\mathrm{O}(2 \mathrm{~W})]$ strongly hydrogen-bonded to the coordinated water molecule $[\mathrm{O}(1 \mathrm{~W})$. .. $\mathrm{O}(2 \mathrm{~W}) 2.744(8) \AA]$.

The dehydrated material, 1e-dehyd, is also built up from a one-dimensional inorganic-organic subnetwork that is, however, markedly distinct from that present in the hydrated $\mathbf{1 e}$ phase (Figure 2). Indeed, the removal of the water molecule and consequent modification of the hedp ${ }^{5-}$ coordinating mode (Scheme S1 in the Supporting Information) leads to the formation of centrosymmetric dimers, formed by $\mu_{2}$-bridging oxygen atoms from two symmetry-related hedp ${ }^{5-}$ ligands, $\left\{\mathrm{Eu}_{2} \mathrm{O}_{4}(\text { hedp })_{2}\right\}$. The $\mathrm{Eu} \cdots \mathrm{Eu}$ intra- and inter-dimeric distances are, respectively, 4.0161(9) and 5.6229(11) $\AA$. The chains are interconnected through shared oxygen atoms $[\mathrm{O}(8)$ and $\mathrm{O}(11)]$ 


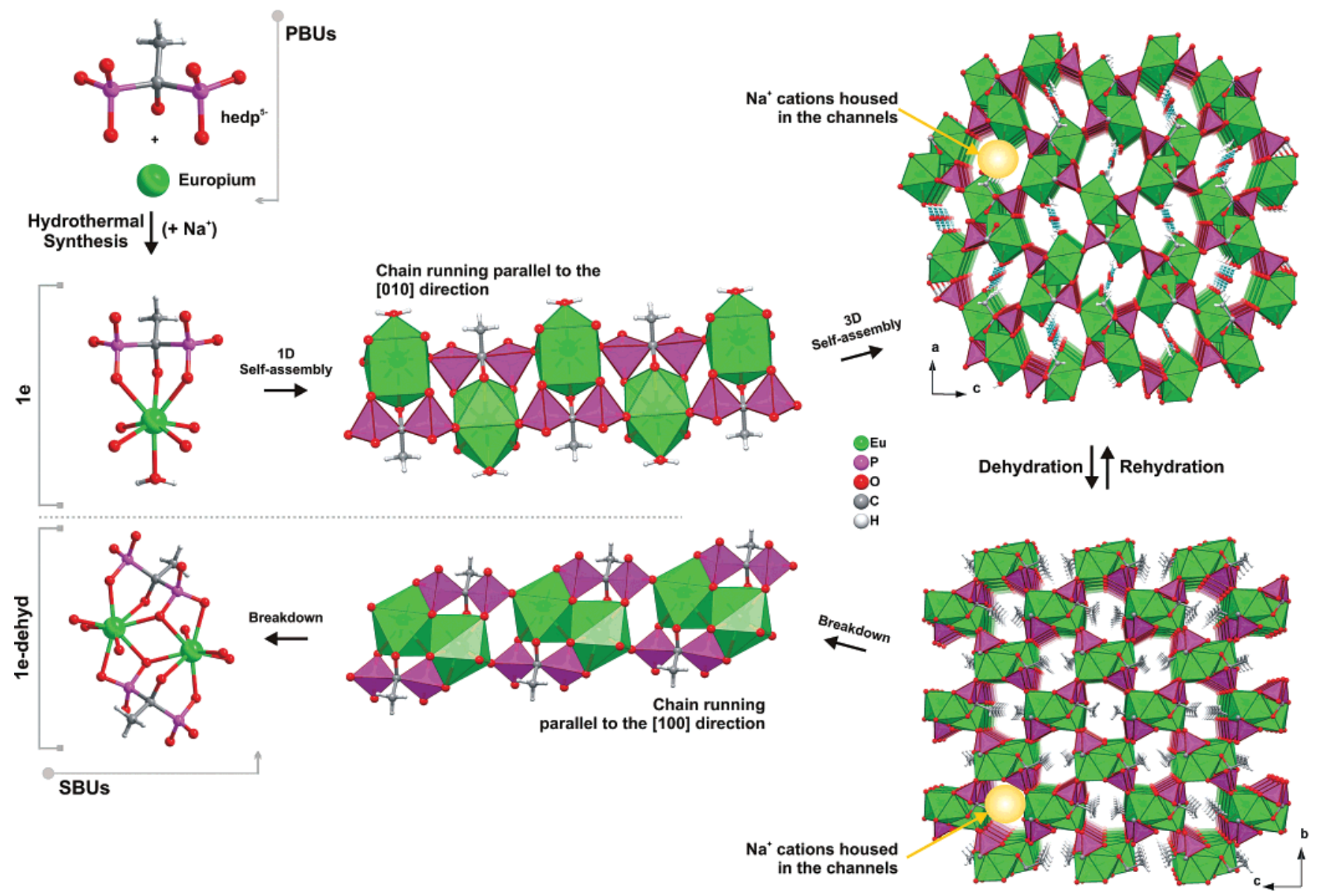

Figure 2. Schematic representation of the self-assembly process (from aqueous solution) leading to the formation of compound 1e and its reversible transformation into 1e-dehyd.

of the phosphonate groups, resulting in an anionic porous 3D network (Figure 2).

The dehydration of $1 \mathrm{e}$ results in the removal of the two different types of water molecules (see following section). 1edehyd retains a framework structure with the same channel system of the parent solid (Figures 2 and S3 in the Supporting Information), but with the $\mathrm{Na}^{+}$cations adopting crystallographic positions closer to lanthanide center and the average crosssection of the channels running parallel to the $a$-axis increasing to ca. $4.0 \times 2.7 \AA^{2}$. These cations seem to stabilize the structure of the dehydrated material, affording structural integrity up to the relatively high temperature of $475^{\circ} \mathrm{C}$ (see below). Moreover, since upon dehydration these cations move closer to the anionic framework, the openness of the structure increases.

These frameworks are conveniently described using a topological approach, that is, by reducing the structures to connecting nodes $\left(\mathrm{Eu}^{3+}\right.$ centers) and bridging rods (direct connections between nodes through the hedp ${ }^{5-}$ ligands). ${ }^{31}$ This procedure, based on mathematical concepts applied to crystal chemistry, yields the immediate taxonomy of the nets. A topological study performed with the software package TOPOS revealed that the two materials are 10-connected uninodal 3D rare-earth organic framekworks with a Schäfli symbol $\left(3^{15} .4^{22} .5^{8}\right)$ (Figure 3$){ }^{32}$

(31) Wells, A. F. Structural Inorganic Chemistry, 4th ed.; Clarendon Oxford University Press: New York, 1975.

(32) (a) Blatov, V. A.; Shevchenko, A. P. TOPOS, v. 4.0 Professional (beta evaluation); Samara State University: Samara, Russia, 2006. (b) Blatov, V. A.; Shevchenko, A. P.; Serezhkin, V. N. J. Appl. Cryst. 2000, 33, 1193.
Thus, it is feasible to assume that the preservation of the global topology for the hydrated and dehydrated materials constitutes an extra factor that permits the observed structural reversibility between these materials. A search in the Reticular Chemistry Structure Resource (RCSR) ${ }^{33}$ and in EPINET ${ }^{34}$ reveals that the nodal connectivity in 1e and 1e-dehyd is reminiscent of that present in FeB.

Between 50 and $300{ }^{\circ} \mathrm{C}$ (Figure 4), 1e gradually loses two types of water molecules (free molecules in the channels and molecules coordinated to $\left.\mathrm{Eu}^{3+}\right)$. As revealed by in situ variabletemperature PXRD, 1e-dehyd is remarkably stable, up to ca. $475^{\circ} \mathrm{C}$ (Figure 4a), above which it decomposes into a mixture of $\mathrm{EuPO}_{4}, \mathrm{NaPO}_{3}$, and $\mathrm{NaEuP}_{2} \mathrm{O}_{7}$. On the basis of PXRD and thermogravimetry data, the dehydration-rehydration process seems to be reversible (Figure $4 \mathrm{~b}, \mathrm{c}$ ), as also reported by Chen et al. for $\left[\mathrm{Co}_{2}(\text { ppca })_{2}\left(\mathrm{H}_{2} \mathrm{O}\right)\left(\mathrm{V}_{4} \mathrm{O}_{12}\right)_{0.5}\right] \cdot 3.62 \mathrm{H}_{2} \mathrm{O}$ [where ppca $=$ 4-(pyridin-4-yl)pyridine-2-carboxylic acid]. ${ }^{35}$ This further suggests that the 1e material may find application as a water sensor since the photoluminescence properties (see dedicated section) may provide, within experimental error, the degree of hydration of the optical center.

The reversibility of this process was further investigated by ${ }^{31} \mathrm{P}$ and ${ }^{23} \mathrm{Na}$ solid-state NMR measurements. ${ }^{23} \mathrm{Na}$, in particular,

(33) RCSR (Reticular Chemistry Structure Resource); http://okeeffe-ws1.la.asu.edu/ RCSR/home.htm.

(34) EPINET; http://epinet.anu.edu.au.

(35) Chen, C. L.; Goforth, A. M.; Smith, M. D.; Su, C. Y.; zur Loye, H. C. Angew. Chem., Int. Ed. 2005, 44, 6673-6677. 

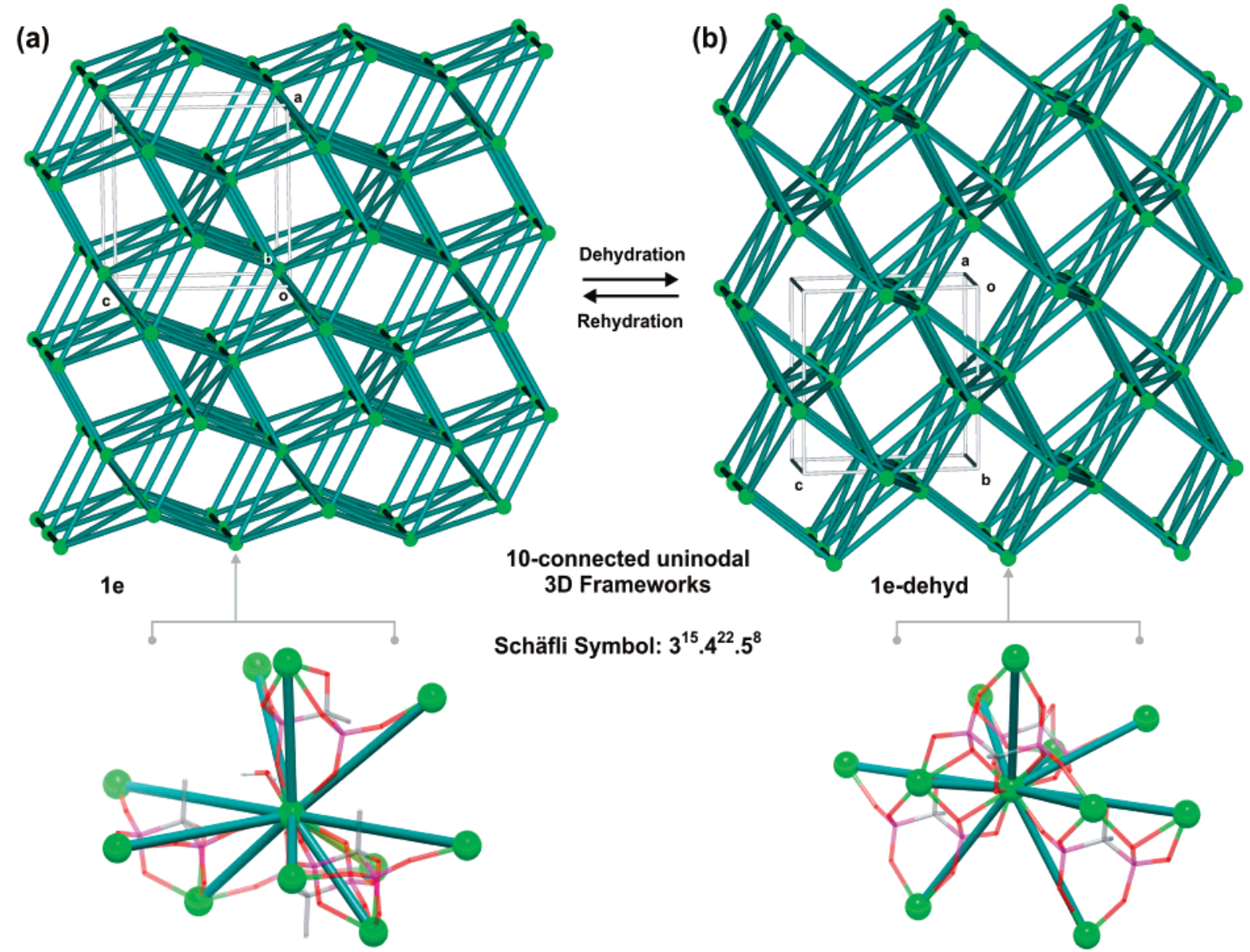

Figure 3. Topological representation of the 10-connected uninodal rare-earth organic frameworks of (a) $1 \mathbf{e}$ and (b) 1e-dehyd: Eu ${ }^{3+}$ centers were taken as the nodes with direct $\mathrm{Eu} \rightarrow \mathrm{Eu}$ connections through hedp ${ }^{5-}$ ligands being substituted by a rod. Intermetallic Eu $\cdots$ Eu distances for 1e: 8.651(2), 7.090(1),

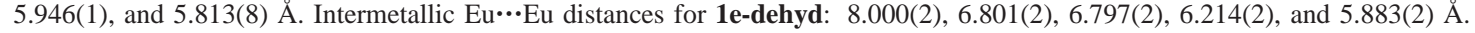

possesses a quadrupole moment and is highly sensitive to electric field gradients generated by the surrounding electronic cloud. The nonparamagnetic La-containing material (1b) was used for the NMR studies. The F1 projection (isotropic dimension) of the ${ }^{23} \mathrm{Na} 3 \mathrm{QMAS}$ NMR spectrum of the as-synthesized material (Figure 5a) exhibits two peaks at ca. 8 and $14 \mathrm{ppm}$. The MAS spectrum (essentially, the F2 projection) was deconvoluted using Gaussian lines (not shown) to give, respectively, 0.4:0.6 populations, in accord with the X-ray single-crystal diffraction studies. Moreover, the 3QMAS NMR spectrum exhibits a distribution of ${ }^{23} \mathrm{Na}$ chemical shifts and quadrupolar coupling parameters, respectively, along the CS and QIS axes. This indicates that the $\mathrm{Na}^{+}$ions are disordered within the pores of the material, as suggested by X-ray diffraction and emphasized in Figure $5 \mathrm{~d}$. The dehydrated material displays a single ${ }^{23} \mathrm{Na}$ resonance (Figure 5b) at $\delta_{1}$ ca. $18 \mathrm{ppm}$, indicating an essentially nondistributed $\mathrm{Na}^{+}$site with little disorder as depicted in Figure 5e. This resonance displays, along the MAS dimension, a typical second-order quadrupolar powder pattern that may be simulated to yield a quadrupole coupling constant $\left(\mathrm{C}_{\mathrm{Q}}\right)$ of $3.7 \mathrm{MHz}$, much larger than the $\mathrm{C}_{\mathrm{Q}}$ values of the resonances given by the hydrated material $(2.0-2.3 \mathrm{MHz})$, considerably shifting the peak from the CS axis along the QIS axis. This suggests that the $\mathrm{Na}^{+}$ions in the hydrated material are significantly more mobile than they are in the dehydrated sample. The as-synthesized and rehydrated samples display very similar spectra (compare Figure 5a and c), confirming that the water adsorption-desorption process is indeed completely reversible.

The ${ }^{31} \mathrm{P}$ CP-MAS NMR spectra of as-synthesized and dehydrated 1b (Figure S4a in Supporting Information) show, respectively, a single resonance at ca. $13.9 \mathrm{ppm}$ and two peaks at ca. 22.3 and $12.8 \mathrm{ppm}$ (1:1 intensity), once again in good agreement with X-ray diffraction studies. After rehydration, the spectrum of the parent sample is restored (Figures S4b and S4c in Supporting Information).

Layered Rare-Earth Organic Materials. Under slightly different synthesis conditions, particularly a low $\mathrm{pH}$ of the initial reactive mixtures (Experimental Section), the same PBUs produce three novel layered rare-earth organic materials, [Eu$\left(\mathrm{H}_{2}\right.$ hedp $\left.)\left(\mathrm{H}_{2} \mathrm{O}\right)_{2}\right] \cdot \mathrm{H}_{2} \mathrm{O}(\mathbf{2 a}),\left[\mathrm{Y}\left(\mathrm{H}_{2}\right.\right.$ hedp $\left.)\left(\mathrm{H}_{2} \mathrm{O}\right)\right] \cdot 3 \mathrm{H}_{2} \mathrm{O}(\mathbf{3 a})$, and $\left[\mathrm{Yb}\left(\mathrm{H}_{2}\right.\right.$ hedp) $] \cdot \mathrm{H}_{2} \mathrm{O}$ (4). A structure identical to $\mathbf{2 a}$ was also isolated and found to contain $\mathrm{Na}^{+}$in the interlayer spaces plus the crystallographically independent $\mathrm{Nd}^{3+}$ center partially substituted by $\mathrm{Ge}^{4+}, \mathrm{Na}_{0.9}\left[\mathrm{Nd}_{0.9} \mathrm{Ge}_{0.10}\left(\right.\right.$ Hhedp) $\left.\left(\mathrm{H}_{2} \mathrm{O}\right)_{2}\right]$ (2b) (see Table 1). Since the main structural features are identical, only the structure of $\mathbf{2} \mathbf{a}$ will be discussed here. $\mathbf{3 b}, \mathbf{a ~ T b}^{3+}$-containing material, is isostructural with $\mathbf{3 a}$ and, thus, only unit cell parameters were collected (Table 1).

Contrasting with the framework structures, the asymmetric units of these layered materials contain the diprotonated $\mathrm{H}_{2}$ hedp $^{3-}$ organic ligand (Figures S5-S7 in Supporting Information). Indeed, the decrease of the number of available 


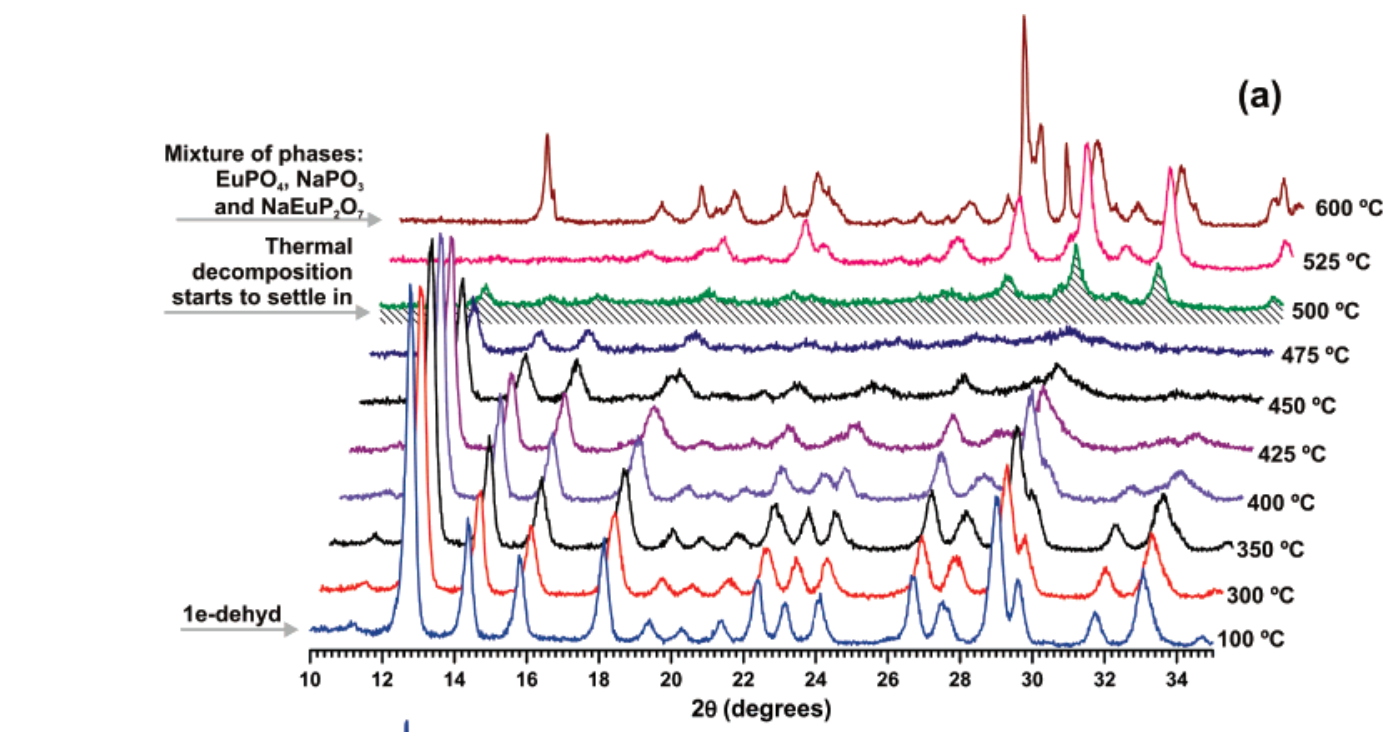

(b)

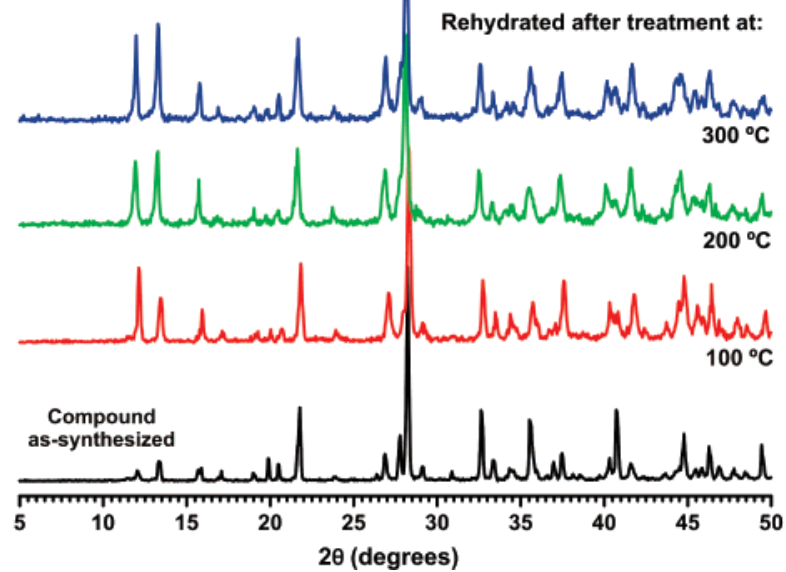

(c)

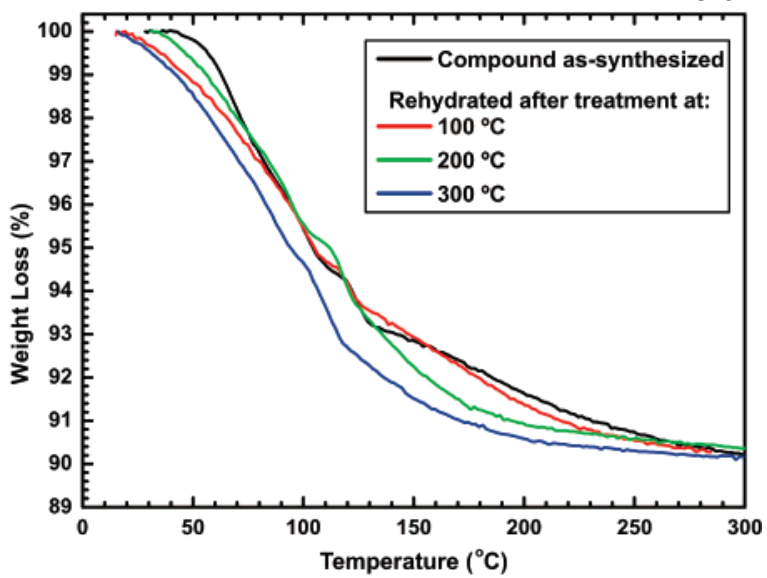

Figure 4. (a) Variable-temperature powder X-ray diffraction data showing the thermal stability of 1e-dehyd up to ca. $475^{\circ} \mathrm{C}$. (b) Powder X-ray diffraction patterns and (c) thermograms of as-synthesized and rehydrated (5 days in a water-saturated atmosphere) 1e material after dehydration at 100, 200, and $300{ }^{\circ} \mathrm{C}(4 \mathrm{~h}$ in air).

coordinating atoms in the organic PBU seems to control the dimensionality of the final materials. In $\mathbf{2 a}$ and $\mathbf{3 a}$, the metal centers are coordinated by eight oxygen atoms, $\left\{\mathrm{MO}_{8}\right\}$ : in the former, the unique $\mathrm{Eu}^{3+}$ center is coordinated to six phosphonate $\mathrm{O}$-atoms belonging to four symmetry-related $\mathrm{H}_{2}$ hedp ${ }^{3-}$ anionic ligands and two $\mathrm{O}$-atoms from crystallographic independent water molecules (Figure S5 in Supporting Information); in 3a six O-atoms belong to phosphonate groups from three symmetry-related $\mathrm{H}_{2}$ hedp $^{3-}$ anionic ligands, with the remaining two coordination positions being occupied by one water molecule and a hydroxyl group (Figure S6 in Supporting Information). These $\left\{\mathrm{MO}_{8}\right\}$ coordination geometries resemble highly distorted dodecahedra, with the $\mathrm{Eu}-\mathrm{O}$ and $\mathrm{Y}-\mathrm{O}$ bond lengths in the $2.306(2)-2.627(2)$ and 2.3098(16)-2.4875(16) $\AA$ ranges, respectively. The internal $\mathrm{O}-\mathrm{M}-\mathrm{O}$ polyhedral angles range from $67.19(8)$ to $152.77(8)^{\circ}$ for $\mathbf{2 a}$, and from $60.50(5)$ to $152.83(6)^{\circ}$ for 3a (Tables S1 and S2 in Supporting Information). In contrast, the crystallographically unique $\mathrm{Yb}^{3+}$ center in $\left[\mathrm{Yb}\left(\mathrm{H}_{2}\right.\right.$ hedp)] $\mathrm{H}_{2} \mathrm{O}$ (4) is coordinated only by six O-atoms, all from phosphonate groups of the $\mathrm{H}_{2}$ hedp ${ }^{3-}$ ligand, in a distorted octahedral $\left\{\mathrm{YbO}_{6}\right\}$ coordination geometry with the $\mathrm{Yb}-\mathrm{O}$ bond lengths, cis and trans $\mathrm{O}-\mathrm{Yb}-\mathrm{O}$ octahedral angles in the 2.149(2)2.330(2) $\AA$, 77.68(8)-104.80(8) ${ }^{\circ}$ and $162.02(8)-175.27(8)^{\circ}$ ranges, respectively (Figure S7 and Table S3 in Supporting Information). Even though the synthesis was performed in aqueous media and the water is included in the crystal structure of 4 , the first coordination sphere of the $\mathrm{Yb}^{3+}$ ions is water free. This structural feature may be rationalized by considering the combined effect of the smaller effective ionic radius of $\mathrm{Yb}^{3+}$ (compared with the other lanthanide ions studied), ${ }^{36}$ and the high connectivity associated with the functional groups of $\mathrm{H}_{2}$ hedp $^{3-}$, which completely trap the metal center. Even when diprotonated, this organic PBU exhibits a variety of coordination modes, as witnessed by the three distinct layered materials reported here (Scheme S2 in the Supporting Information). $\mathrm{Yb}^{3+}$ is also the metal center, among all used in this paper, coordinated to the largest number (five) of symmetry-related $\mathrm{H}_{2}$ hedp ${ }^{3-}$ ligands, a structural feature clearly reflected in the taxonomy aspects of the material (see below).

Self-recognition in solution of the PBUs of 2a, 3a, and $\mathbf{4}$ leads to the self-assembly of the layered networks, which can be envisaged as composed by centrosymmetric dinuclear hypothetical SBUs (Figure 6), with intra-dimeric $\mathrm{Eu}(1) \cdots \mathrm{Eu}-$ $(1)^{\mathrm{i}}, \mathrm{Y}(1) \cdots \mathrm{Y}(1)^{\mathrm{ii}}$, and $\mathrm{Yb}(1) \cdots \mathrm{Yb}(1)^{\mathrm{iii}}$ distances of, respectively,

(36) (a) Shannon, R. D. Acta Cryst. A 1976, 32, 751-767. (b) Shannon, R. D.; Prewitt, C. T. Acta Cryst. B 1969, 25, 925-946. 

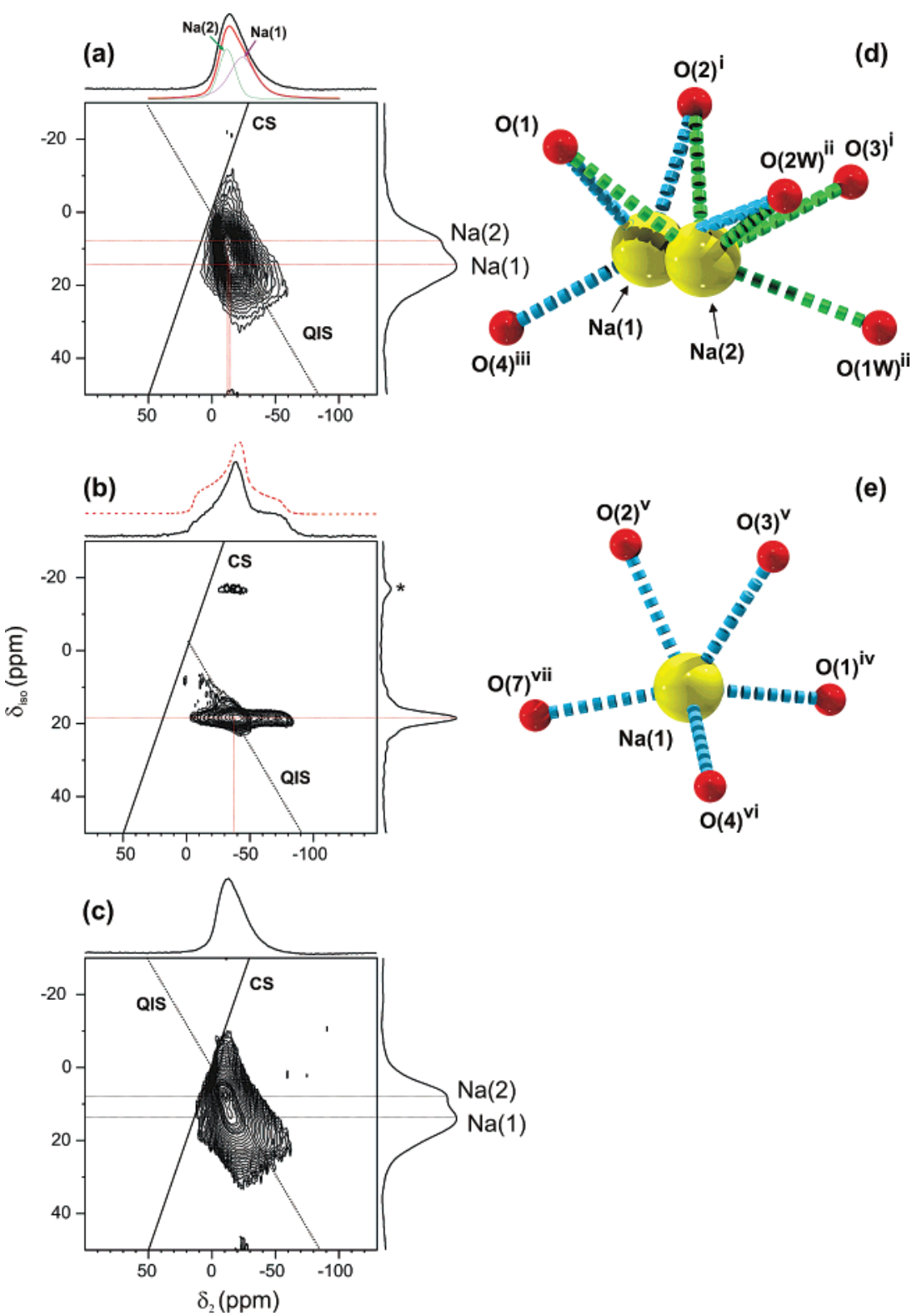

Figure 5. Sheared ${ }^{23} \mathrm{Na} 3 \mathrm{QMAS}$ NMR spectra of (a) as-synthesized, (b) dehydrated at $300{ }^{\circ} \mathrm{C}$, and (c) rehydrated $\mathbf{1 b}$. CS and QIS are, respectively, the chemical shift and quadrupolar induced shift axes. The dashed line in (b) is the simulated second-order quadrupolar powder pattern, which yields a quadrupolar coupling constant of ca. $3.70 \mathrm{MHz}$ and an asymmetry parameter of ca. 0.88 . The asterisk denotes a spinning sideband. Chemical environments of $\mathrm{Na}^{+}$

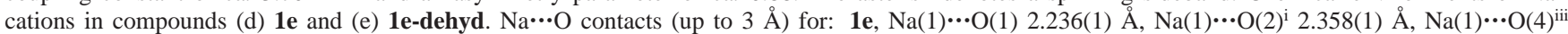
$2.422(1) \AA, \mathrm{Na}(1) \cdots \mathrm{O}(2 \mathrm{~W})^{\mathrm{ii}} 2.921(1) \AA, \mathrm{Na}(2) \cdots \mathrm{O}(1) 2.646(1) \AA, \mathrm{Na}(2) \cdots \mathrm{O}(2)^{\mathrm{i}} 2.665(1) \AA, \mathrm{Na}(2) \cdots \mathrm{O}(3)^{\mathrm{i}} 2.941(1) \AA, \mathrm{Na}(1) \cdots \mathrm{O}(1 \mathrm{~W})^{\mathrm{ii}} 2.712(1) \AA, \mathrm{Na}-$ $(2) \cdots \mathrm{O}(2 \mathrm{~W})^{\mathrm{ii}} 2.110(1) \AA$; 1e-dehyd, $\mathrm{Na}(1) \cdots \mathrm{O}(1)^{\mathrm{iv}} 2.264(16) \AA, \mathrm{Na}(1) \cdots \mathrm{O}(2)^{\mathrm{v}} 2.413(17) \AA, \mathrm{Na}(1) \cdots \mathrm{O}(3)^{\mathrm{v}} 2.545(17) \AA, \mathrm{Na}(1) \cdots \mathrm{O}(4)^{\mathrm{vi}} 2.415(18) \AA, \mathrm{Na}-$ (1) $\cdots \mathrm{O}(7)^{\mathrm{vii}} 2.418(17) \AA$. Symmetry transformations used to generate equivalent atoms: (i) $1 / 2+x, y, 1 / 2-z$; (ii) $2.5-x,-y, 1 / 2+z$; (iii) $2-x$, $1 / 2+y,-z$; (iv) $-1+x, y, z$; (v) $-1+x, 1.5-y, 1 / 2+z$; (vi) $1-x, 2-y, 1-z$; (vii) $x, 1.5-y, 1 / 2+z$.

4.0864(1), 3.9714(3), and 3.6058(2) $\AA$ [symmetry codes: (i) $-x, 2-y, 1-z$; (ii) $-1-x,-y,-z$; (iii) $1-x,-y, 1-z]$. Indeed, even though at this stage there is no experimental evidence for the isolation of these SBUs in solution or in the solid state, these hypothetical chemical entities present a convenient way to fully describe the formation of the REOFs. In $\mathbf{2 a}$ and $\mathbf{3 a}$, SBUs self-assemble in the $a b$ or $b c$ planes in brick-wall or herringbone fashions, respectively, via shared oxygen atoms of phosphonate groups $[\mathrm{O}(1), \mathrm{O}(2)$, and $\mathrm{O}(7)$ for $\mathbf{2 a} ; \mathrm{O}(4)$ and $\mathrm{O}(7)$ for 3a], leading to the formation of neutral layered $\infty_{\infty}^{2}\left[\mathrm{Eu}\left(\mathrm{H}_{2}-\right.\right.$ hedp) $\left.\left(\mathrm{H}_{2} \mathrm{O}\right)_{2}\right]$ and $\infty_{\infty}^{2}\left[\mathrm{Y}\left(\mathrm{H}_{2}\right.\right.$ hedp) $\left.\left(\mathrm{H}_{2} \mathrm{O}\right)\right]$ (Figure 6, top and medium rows, respectively). Topological investigations of these plane nets using TOPOS ${ }^{32}$ reveals that $\mathbf{2 a}$ is a novel 8-connected uninodal net, Schläfli symbol $3^{12} .4^{14} .5^{2}$, and $\mathbf{3 a}$ is a 5-connected uninodal Shubnikov-type plane net, Schläfli symbol $3^{3} \cdot 4^{3} \cdot 5^{4}$. However, the topological features of $\mathbf{2 a}$ are more complex because this network may be envisaged as a self-penetrating two-dimensional plane net (two nets interweaved), with the shortest circuit being 4-gons. The fact that all nodes are common to the two networks further evidence the rarity of this topological feature. ${ }^{2}$ The structural robustness within these $2 \mathrm{D}$ plane nets is further assured by extensive and cooperative $\mathrm{O}-\mathrm{H} \cdots \mathrm{O}$ hydrogen-bonding interactions between the coordinated water molecules, hydroxyl groups, protonated $(\mathrm{P}-\mathrm{OH})$ and deprotonated $(\mathrm{P}-\mathrm{O})$ groups (dashed blue bonds in Figure 6). Individual layers close pack along the [001] (2a) or [100] (3a) directions with the interlayer spaces being filled-up with water molecules of crystallization (one and three crystallographically indepen- 


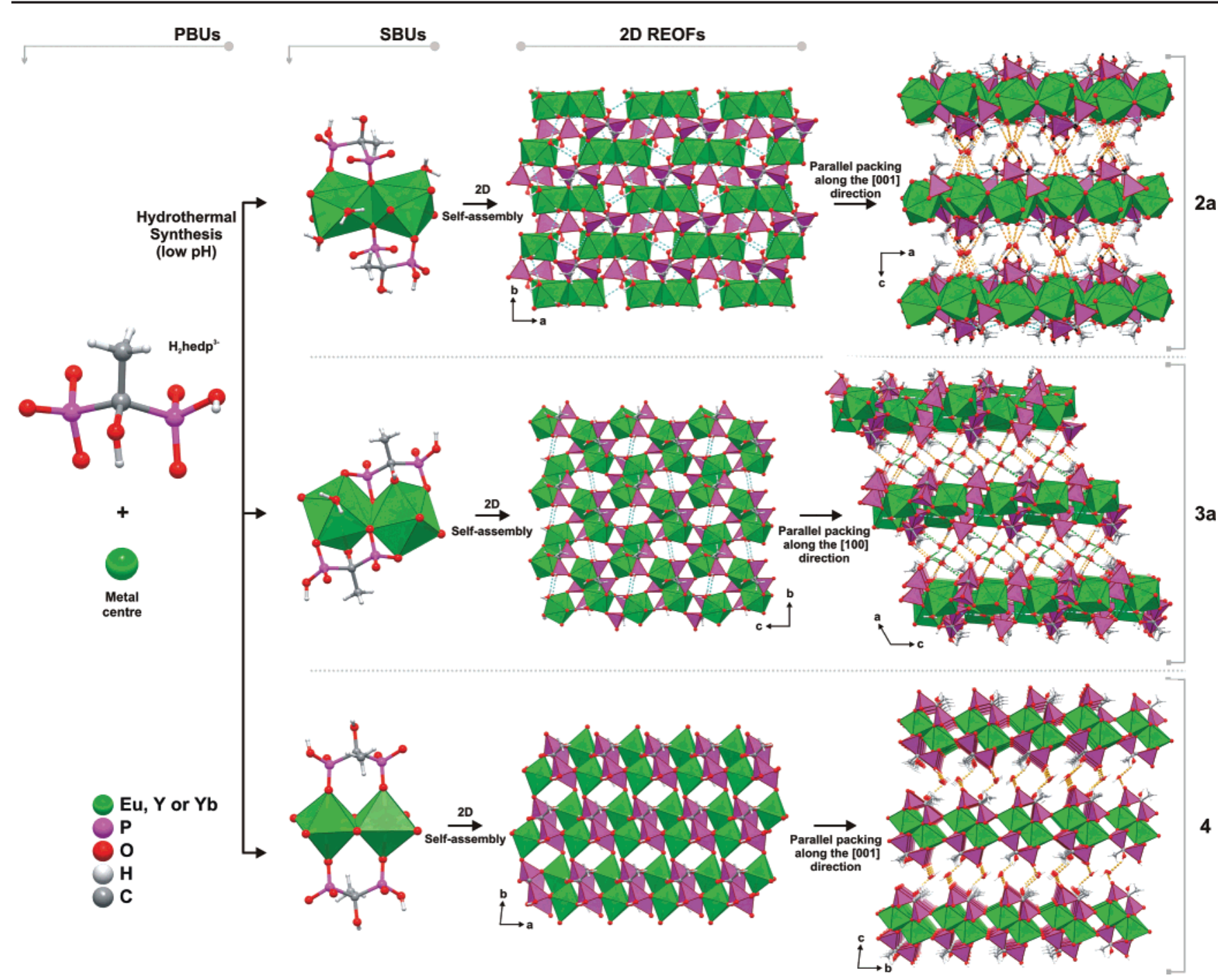

Figure 6. Schematic representation of the self-assembly process leading to the formation of $\left[\mathrm{Eu}\left(\mathrm{H}_{2}\right.\right.$ hedp $\left.)\left(\mathrm{H}_{2} \mathrm{O}\right)_{2}\right] \cdot \mathrm{H}_{2} \mathrm{O}(\mathbf{2 a}),\left[\mathrm{Y}\left(\mathrm{H}_{2}\right.\right.$ hedp) $\left.\left(\mathrm{H}_{2} \mathrm{O}\right)\right] \cdot 3 \mathrm{H}_{2} \mathrm{O}(\mathbf{3 a})$, and $\left[\mathrm{Yb}\left(\mathrm{H}_{2}\right.\right.$ hedp) $] \cdot \mathrm{H}_{2} \mathrm{O}(4)$. Intra-layer hydrogen bonds, those involving the crystallization water molecules and the layers, plus those within the water clusters are depicted as dashed blue, orange, and green lines, respectively.

dent, respectively), which are further engaged in a series of hydrogen-bonding interactions (dashed orange bonds in Figure 6; see also Table S4 in the Supporting Information).

Remarkably, in 3a, the three crystallographically independent, noncoordinated, water molecules of crystallization $[\mathrm{O}(2 \mathrm{~W})$, $\mathrm{O}(3 \mathrm{~W})$ and $\mathrm{O}(4 \mathrm{~W})]$ are engaged in cooperative water-to-water hydrogen-bonding interactions, leading to the formation of a $\left(\mathrm{H}_{2} \mathrm{O}\right)_{13}$ cluster, structurally resembling a bicyclic hexameric and decameric building unit (Figure 7a): $R_{6}^{4}(12)$ and $R_{10}{ }^{8}(20)$ graph set motifs, respectively. ${ }^{37}$ This unit constitutes the basis of the 2D network of water present within the interlayer space depicted in Figure 7b. Even though a number of recent reports describe various types of discrete water clusters (such as tetramers, pentamers, hexamers, octamers, decamers, dodecamers) and a few polymeric clusters (essentially infinite chains), complete crystallographic descriptions of highly ordered 2D aggregates of uncoordinated water molecules are much more scarce. To the best of our knowledge, the $2 \mathrm{D}$ water cluster present in 3a, consisting only of uncoordinated water molecules, is unprecedented. Interest on discrete and infinite water clusters

(37) Bernstein, J.; Davis, R. E.; Shimoni, L.; Chang, N. L. Angew. Chem., Int. Ed. 1995, 34, 1555-1573. present in inorganic, organic, and hybrid organic-inorganic compounds has increased in recent years, mainly because it may contribute to a better understanding of the behavior of water in confined spaces, for example, as it is found in certain biological systems. ${ }^{39}$ In 3a, both decameric and hexameric water rings exhibit the typical stable chair conformation, with the internuclear $\mathrm{O} \cdots \mathrm{O}$ distances ranging from $2.761(3)$ to $2.933(3) \AA$, with an average value of 2.841(3) $\AA$, which is close to the internuclear distance in liquid water $(2.85 \AA),{ }^{40}$ thus conferring the material great potential for being used as a model for studying water in confined spaces. Moreover, the hydrogenbonding interactions in this cluster are also strongly linear, with the $<$ (DHA) interaction angles ranging from $159(3)$ to $176(2)^{\circ}$ (see Table S4 in the Supporting Information for details on the geometry of individual hydrogen bonds).

Due to the smaller effective ionic radius of $\mathrm{Yb}^{3+}$, the crystal structure of $\left[\mathrm{Yb}\left(\mathrm{H}_{2}\right.\right.$ hedp) $] \cdot \mathrm{H}_{2} \mathrm{O}$ (4) is distinct from those

(38) (a) Infantes, L.; Chisholm, J.; Motherwell, S. CrystEngComm 2003, 5, 480486. (b) Infantes, L.; Motherwell, S. CrystEngComm 2002, 454-461. (c) Mascal, M.; Infantes, L.; Chisholm, J. Angew. Chem., Int. Ed. 2006, 45, 32-36.

(39) Ludwig, R. Angew. Chem., Int. Ed. 2001, 40, 1809-1827.

(40) Narten, A. H.; Hahn, R. L. Science 1982, 217, 1249-1250. 

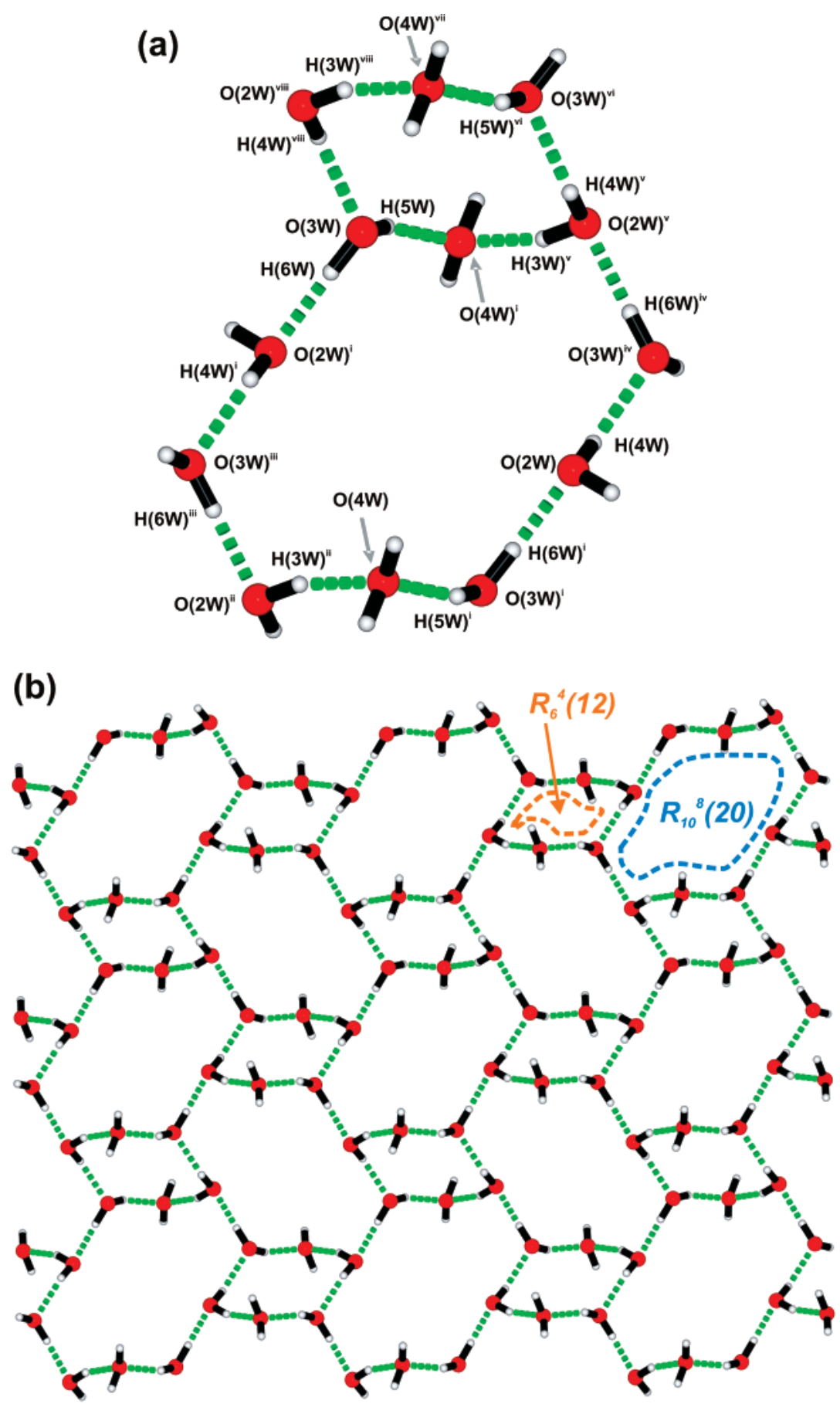

Figure 7. (a) Detailed view of the $R_{6}{ }^{4}(12)$ and $R_{10}{ }^{8}(20)$ graph set motifs ${ }^{37}$ formed by water molecules in $3 \mathbf{a}$, showing the labeling scheme for all atoms directly involved in the water-to-water hydrogen bonds. For details on the hydrogen-bonding geometries, see Table S4 in the Supporting Information. Symmetry transformations used to generate equivalent atoms: (i) $2-x,-y,-z$; (ii) $x,-y-1 / 2, z-1 / 2$; (iii) $2-x, y-1 / 2,-z-1 / 2$; (iv) $2-x, y-1 / 2,1 / 2-z$; (v) $2-x, y+1 / 2,1 / 2-z$; (vi) $2-x, 1-y,-z$; (vii) $x, 1+y, z$; (viii) $x, 1 / 2-y, z-1 / 2$. (b) Extended view of the $2 \mathrm{D}$ water cluster present in 3a.

previously described. A centrosymmetric dimeric SBU selfassembles in a parallel fashion along the [100] direction of the unit cell, forming a 1D sub-network with the closest and longest Yb $\cdots$ Yb intrachain distances being 3.6058(2) $\AA$ (intra-dimeric distance) and 7.180(4) A, respectively. Adjacent chains interconnect along the [010] direction via the bridging deprotonated phosphonate group $[\mathrm{P}(1)-\mathrm{O}(3)]$, imposing a $\mathrm{Yb} \cdots \mathrm{Yb}$ distance of 4.8380(2) $\AA$ and leading to the formation of neutral undulated layers $\infty_{\infty}^{2}\left[\mathrm{Yb}\left(\mathrm{H}_{2}\right.\right.$ hedp) $]$ in the $a b$ plane of the unit cell (Figure 6 , bottom row). This rather dense $2 \mathrm{D}$ rare-earth organic material is topologically characterized as a remarkable 11-connected uninodal undulated net, Schläfli symbol $3^{27} \cdot 4^{26} .5^{2}$ (Figure S8 in Supporting Information). To the best of our knowledge, this topology is unique, as confirmed with the software package TOPOS $^{32}$ in conjunction with searches in the literature and RCSR. ${ }^{33}$ Moreover, a search in EPINET reveals that this topology has also not yet been enumerated. ${ }^{34}$

Contrasting with $\mathbf{2} \mathbf{a}$ and $\mathbf{3 a}$, in $\mathbf{4}$, there are no $\mathrm{O}-\mathrm{H} \cdots \mathrm{O}$ intralayer hydrogen bonding interactions, despite the presence of a single-protonated phosphonate group and the hydroxyl group in the organic PBU. Individual ${ }_{\infty}^{2}\left[\mathrm{Yb}\left(\mathrm{H}_{2}\right.\right.$ hedp $\left.)\right]$ layers close pack along the [001] direction with the interlayer spaces being filled- 


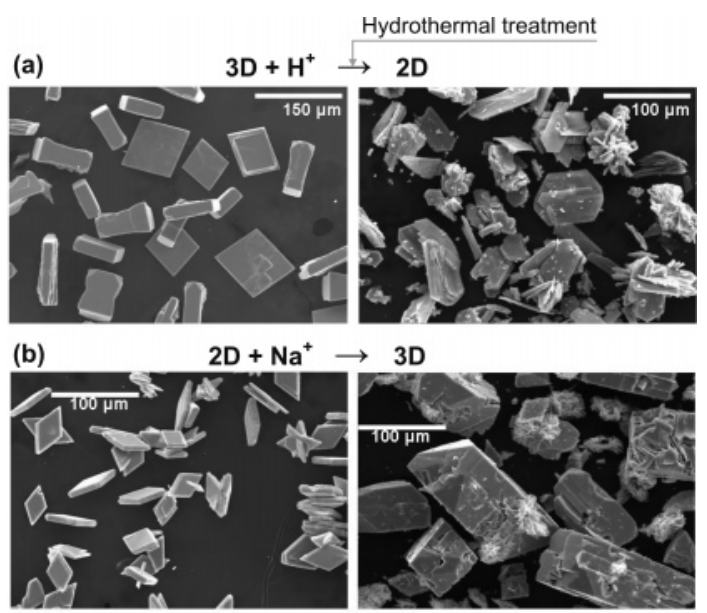

Figure 8. SEM images of the materials used to study the interconversion of framework (3D) and layered (2D) rare-earth organic coordination polymers under hydrothermal conditions, in the presence of $\mathrm{H}^{+}$and $\mathrm{Na}^{+}$. Each pair of images was taken for the same material, before and after the transformation.

up with water molecules of crystallization, which are further involved in strong and highly directional hydrogen-bonding interactions (Table S4 in the Supporting Information).

Interconversion of Framework and Layered Rare-Earth Organic Materials. The $\mathrm{pH}$ of the initial reactive mixtures is a key factor determining the dimensionality of the final product. Indeed, the protonation of the phosphonate or hydroxyl groups of the organic PBU changes the number of available connecting atoms in the ligand, and consequently, the structural connectivity is affected. To study this effect, we have treated, under hydrothermal conditions, the framework $1 \mathrm{~g}$ with a $\mathrm{HCl}$ solution and obtained a product consisting of plate-like crystals (Figure $8 \mathrm{a}$, whose structure was revealed by single-crystal X-ray diffraction to be identical to the structure of layered $\mathbf{3 b}$ (crystal size $0.10 \times 0.05 \times 0.02 \mathrm{~mm}^{3}$, colorless plate, $100(2) \mathrm{K}$, monoclinic $P, a=11.16 \AA, b=9.14 \AA, c=11.58 \AA, \alpha=\beta$ $=90^{\circ}, \gamma=111.53^{\circ}$, volume $=1100 \AA^{3}$ ). To investigate whether the inverse reaction from layered to framework materials was possible, a layered $\mathrm{Tb}^{3+}$-containing material isostructural with 2a was hydrothermally treated with sodium chloride. The crystalline product (Figure $8 \mathrm{~b}$ ) is indeed a framework solid of family 1 (crystal size $0.12 \times 0.10 \times 0.05 \mathrm{~mm}^{3}$, colorless prism, $100(2) \mathrm{K}$, orthorhombic $P, a=8.55 \AA, b=9.98 \AA, c=10.59$ $\AA, \alpha=\beta=\gamma=90^{\circ}$, volume $=903 \AA^{3}$ ). This control of the dimensionality of rare-earth organic materials by the addition of acid or salt does not seem to have been previously reported for phosphonic-based REOFs. We note that, at present, it is unclear whether these transformations occur via a single-crystalto-single-crystal process or, alternatively, via a dissolution/ recrystallization route.

To rationalize the peculiar interconversion behavior of these compounds, consider first a slice of the $a b$ plane of the 10connected uninodal framework of 1e (Figure 9, dark purple). This new undulated subnetwork consists of 6- and 8-connected nodes. As revealed by the dehydration-rehydration study of 1e, the organic PBU used exhibits a remarkable coordination flexibility. Thus, it is fair to assume that by compressing this sub-network (a process driven mainly by the formation of new coordinative connections that stabilize the first-coordination sphere of the lanthanides) the six-connecting node establishes two new bridges, becoming 8-connected. The resulting framework (uninodal with 8 -connecting nodes) is topologically identical to structure 2a (Figure 9, bottom left). This is in accord with the synthetic route employed: the addition of $\mathrm{H}^{+}$to the system breaks a number of coordinative $\mathrm{Ln}-\mathrm{O}$ bonds, with the resulting "free" terminal $\mathrm{P}-\mathrm{O}^{-}$seeking neighboring lanthanides to establish new connections. Alternatively, if one considers the 5 -connected network of $\mathbf{3 a}$, the addition of the $\mathrm{Na}^{+}$counterions to the reactive mixture prompts the condensation of identical nets (the removal of protonating $\mathrm{H}^{+}$is compensated by the inclusion of $\mathrm{Na}^{+}$), thus leading to the channels of $\mathbf{1 e}$ depicted in Figure S3b in the Supporting Information.

Photoluminescence Properties of Eu-Organic Frameworks. Figure 10 compares the excitation spectra of $1 \mathbf{e}$ during a hydration cycle, monitored at the more intense ${ }^{7} F_{2}$ Stark component. The spectrum of the as-synthesized material exhibits a series of sharp intra- $4 \mathrm{f}^{6}$ transitions and a broad band (LS) centered at ca. $250 \mathrm{~nm}$, ascribed to the spin-allowed interconfigurational $4 f^{6} \rightarrow 4 f^{5} 5 d^{1}$ band of $\mathrm{Eu}^{3+} .^{41}$ After dehydration, the relative intensity of the LS fd inter-configurational band increases relatively to the intensity of the $\mathrm{Eu}^{3+}$ lines, indicating a modification in the excitation paths of the ${ }^{5} \mathrm{D}_{0}$ level, consistent with the removal of water. The spectra of the as-prepared and rehydrated materials are similar, indicating that the dehydrationrehydration process is reversible, in agreement with the X-ray diffraction and solid-state NMR studies described in the previous sections.

Figure 11 shows the high-resolution emission spectra of assynthesized 1e obtained for two selected excitation wavelengths. The emission spectrum displays the typical $\mathrm{Eu}^{3+}$ intra- $4 \mathrm{f}^{6}$ lines ascribed to the ${ }^{5} \mathrm{D}_{0} \rightarrow{ }^{7} \mathrm{~F}_{0-4}$ transitions, whose energy and number of Stark components (i.e., 3, and $5{ }^{5} \mathrm{D}_{0} \rightarrow{ }^{7} \mathrm{~F}_{1,2}$ transitions, respectively) is independent of the excitation wavelength. This observation and the fact that only one line is observed for the ${ }^{5} \mathrm{D}_{0} \rightarrow{ }^{7} \mathrm{~F}_{0}$ transition suggest that the $\mathrm{Eu}^{3+}$ ions occupy the same average local environment in both materials. Dehydration induces prominent changes in the $\mathrm{Eu}^{3+}$ emission lines, namely in the energy, full-width-at-half-maximum and number of Stark components, which decreases (most evident for the ${ }^{5} \mathrm{D}_{0} \rightarrow{ }^{7} \mathrm{~F}_{1}$ transition, which displays two lines) and red-shifts the ${ }^{5} \mathrm{D}_{0} \rightarrow{ }^{7} \mathrm{~F}_{0}$ transition. The decrease of the energy of the latter transition indicates that, on average, the $\mathrm{Eu}-\mathrm{O}$ bonds are slightly less covalent in the dehydrated material. ${ }^{42}$ This is in accord with the X-ray diffraction evidence because, on dehydration, the median of the Eu-O bond lengths increases from ca. 2.37 to $2.40 \AA$ (Table 2). After re-hydration the emission spectra resembles those of the as-synthesized material indicating a reversibility of the $\mathrm{Eu}^{3+}$ local environment.

The ${ }^{5} \mathrm{D}_{0}$ emission-decay curves, monitored within the ${ }^{5} \mathrm{D}_{0} \rightarrow{ }^{7} \mathrm{~F}_{2}$ lines for the two excitation wavelengths used to acquire the emission spectra in Figure 11, are mono exponentials, indicating the presence of a single $\mathrm{Eu}^{3+}$ local environment. For all materials, the lifetime values (Table 3, absolute error 5\%) are independent of the excitation wavelength. The ${ }^{5} \mathrm{D}_{0}$ lifetimes of

(41) Ananias, D.; Kostova, M.; Paz, F. A. A.; Ferreira, A.; Carlos, L. D.; Klinowski, J.; Rocha, J. J. Am. Chem. Soc. 2004, 126, 10410-10417.

(42) (a) Frey, S. T.; Horrocks, W. D. W. Inorg. Chim. Acta 1995, 229, 383390. (b) Malta, O.; Batista, H. J.; Carlos, L. D. Chem. Phys. 2002, 282, 21-30. (c) Carlos, L. D.; Malta, O.; Albuquerque, R. Q. Chem. Phys. Lett. $\mathbf{2 0 0 5}, 415,238-242$. 


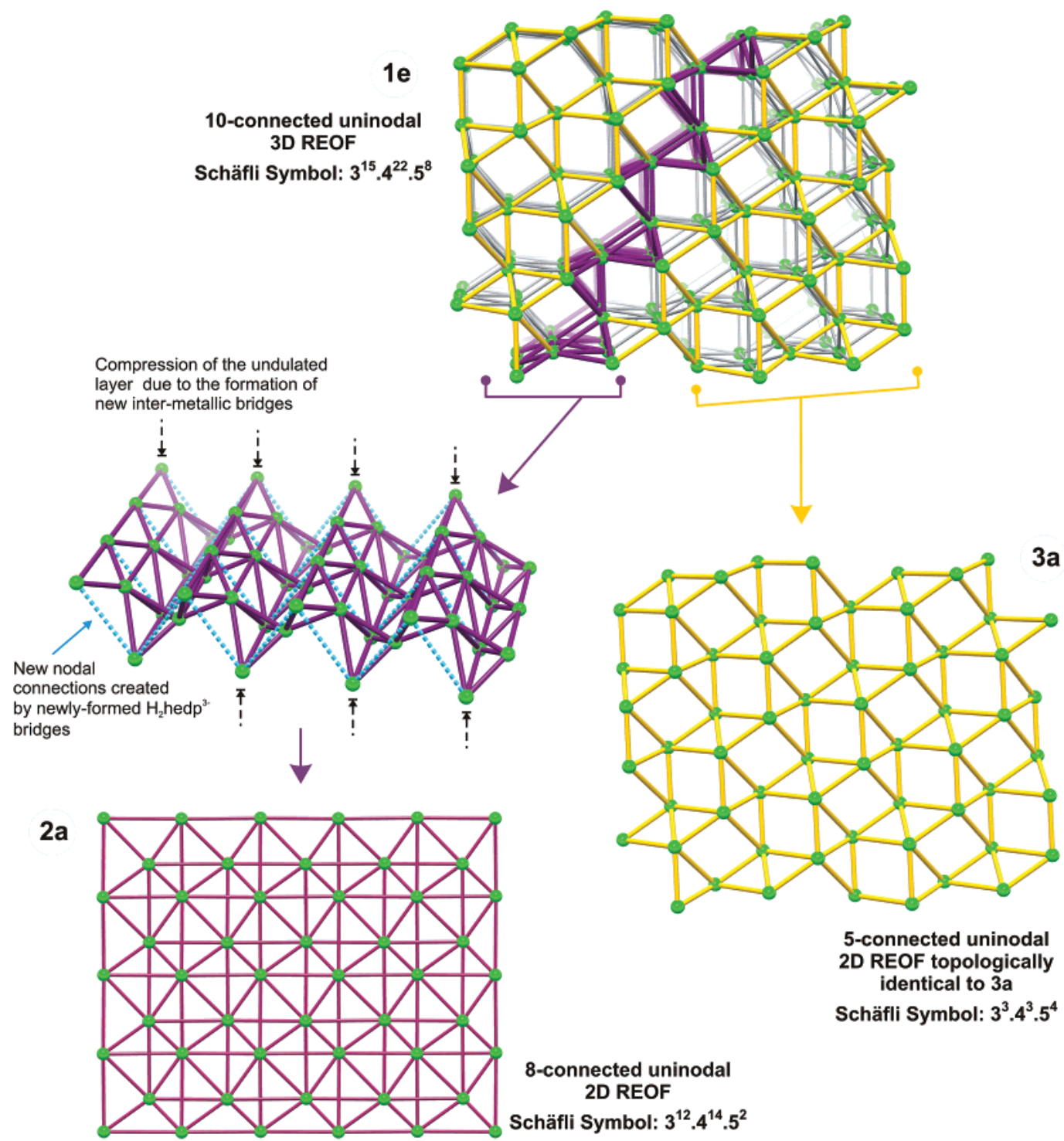

Figure 9. Topological representation of the breakdown of the 10-connected uninodal three-dimensional (3D) network of 1e into the 8- and 5-connected two-dimensional (2D) plane nets of $\mathbf{2 a}$ and $\mathbf{3 a}$, respectively. $\mathrm{Eu}^{3+}$ centers were taken as the nodes with direct Eu $\rightarrow$ Eu connections through hedp ${ }^{5-}$ ligands being substituted by a rod. Intermetallic Eu $\cdots$ Eu distances for 2a: 6.943(1), 6.839(1), 5.673(1), 4.931(1), and 4.086(1) A. Intermetallic Eu $\cdots$ Eu distances for 3a: $6.280(1), 5.660(1)$, and 3.971(1) $\AA$.

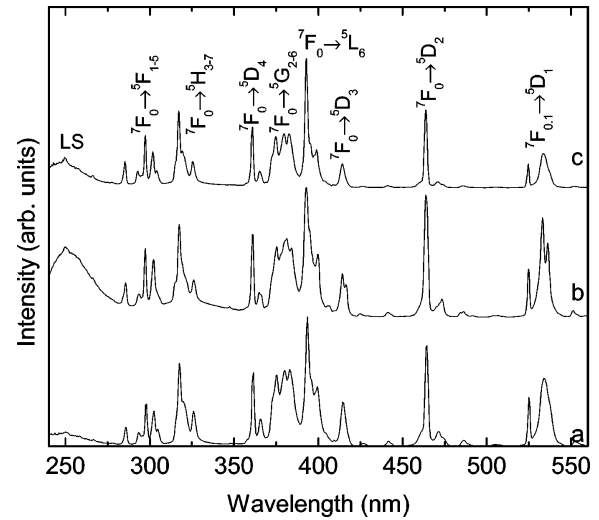

Figure 10. Excitation spectra of (a) as-synthesized, (b) dehydrated, and (c) rehydrated 1e, monitored at $612 \mathrm{~nm}$.

as-synthesized and rehydrated solids are similar, whereas the dehydrated material exhibits a larger lifetime.

From the emission spectra and ${ }^{5} \mathrm{D}_{0}$ lifetime values, it is possible to estimate the efficiency, $q$, of the ${ }^{5} \mathrm{D}_{0}$ state and infer

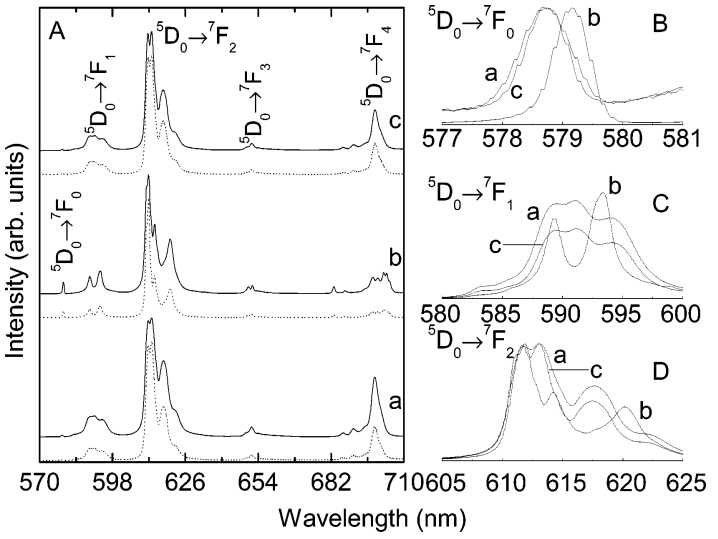

Figure 11. (A) Emission spectra of (a) as-synthesized, (b) dehydrated, and (c) rehydrated 1e, excited at 250 (dotted lines) and $395 \mathrm{~nm}$ (solid lines). (B-D) ${ }^{5} \mathrm{D}_{0} \rightarrow{ }^{7} \mathrm{~F}_{0-2}$ transitions in detail, respectively.

the presence of water molecules in the first coordination sphere of $\mathrm{Eu}^{3+}$. Assuming that only nonradiative and radiative processes 
Table 3. ${ }^{5} D_{0}$ Lifetime $(\tau, \mathrm{Ms})$ of As-Synthesized, Dehydrated, and Rehydrated 1e Frameworks, Monitored at $613 \mathrm{~nm}$ at Different Excitation Wavelengths $\left(\lambda_{\text {ex }}, \mathrm{nm}\right)$

\begin{tabular}{cccc}
\hline$\lambda_{\text {ex }}$ & as-synthesized & dehydrated & rehydrated \\
\hline 250 & $0.570 \pm 0.001$ & $1.118 \pm 0.002$ & $0.618 \pm 0.002$ \\
395 & $0.589 \pm 0.002$ & $1.116 \pm 0.002$ & $0.628 \pm 0.002$ \\
\hline
\end{tabular}

are involved in the depopulation of the ${ }^{5} \mathrm{D}_{0}$ state, $q$ may be defined as:

$$
q=\frac{k_{\mathrm{r}}}{k_{\mathrm{r}}+k_{\mathrm{nr}}}
$$

where $k_{\mathrm{r}}$ and $k_{\mathrm{nr}}$ are the radiative and nonradiative transition probabilities, respectively $\left(k_{\exp }=\tau_{\exp }^{-1}\right.$ is the experimental transition probability). The emission intensity, $I$, taken as the integrated intensity $S$ of the emission lines for the ${ }^{5} \mathrm{D}_{0} \rightarrow{ }^{7} \mathrm{~F}_{0-6}$ transitions, is:

$$
I_{\mathrm{i} \rightarrow j}=\hbar w_{\mathrm{i} \rightarrow j} A_{\mathrm{i} \rightarrow j} N i \equiv S_{\mathrm{i} \rightarrow j}
$$

where $i$ and $j$ are the initial $\left({ }^{5} \mathrm{D}_{0}\right)$ and final $\left({ }^{7} \mathrm{~F}_{0-6}\right)$ levels, respectively, $\hbar w_{i \rightarrow j}$ is the transition energy, $A_{i \rightarrow j}$ is the Einstein coefficient of spontaneous emission, and $N_{i}$ is the population of the ${ }^{5} \mathrm{D}_{0}$ emitting level. ${ }^{43,44}$ Due to the lower relative intensity of the ${ }^{5} \mathrm{D}_{0} \rightarrow{ }^{7} \mathrm{~F}_{5,6}$ transitions, their contribution is neglected, and the depopulation of the ${ }^{5} \mathrm{D}_{0}$ excited state, and consequently the radiative contribution, is estimated based only on the relative intensities of the ${ }^{5} \mathrm{D}_{0} \rightarrow{ }^{7} \mathrm{~F}_{0-4}$ transitions. $k_{\mathrm{r}}$ may be calculated as:

$$
k_{\mathrm{r}}=A_{0 \rightarrow 1} \frac{\hbar \omega_{0 \rightarrow 1}}{S_{0 \rightarrow 1}} \sum_{J=0}^{4} \frac{S_{0-J}}{\hbar \omega_{0-J}}
$$

where $A_{0 \rightarrow 1}$ is the Einstein coefficient of spontaneous emission between the ${ }^{5} \mathrm{D}_{0}$ and the ${ }^{7} \mathrm{~F}_{1}$ Stark levels. The magnetic dipoleallowed ${ }^{5} \mathrm{D}_{0} \rightarrow{ }^{7} \mathrm{~F}_{1}$ transition was taken as reference, in vacuo $A_{\mathrm{RAD}}\left({ }^{5} \mathrm{D}_{0} \rightarrow{ }^{7} \mathrm{~F}_{1}\right)=14.65 \mathrm{~s}^{-1} \cdot{ }^{44}$ An average refraction index of 1.5 was considered, leading to $A_{\mathrm{RAD}}\left({ }^{5} \mathrm{D}_{0} \rightarrow{ }^{7} \mathrm{~F}_{1}\right) \approx 50 \mathrm{~s}^{-1} .43$

The number of water molecules $\left(n_{\mathrm{w}}\right)$ coordinated to $\mathrm{Eu}^{3+}$ may be determined using the empirical formula of Supkowski and Horrocks: ${ }^{45}$

$$
n_{\mathrm{w}}=1.11 \times\left[k_{\exp }-k_{\mathrm{r}}-0.31\right]
$$

One may use for $k_{\mathrm{r}}$ the value obtained in $\mathrm{D}_{2} \mathrm{O} .{ }^{45}$ The ${ }^{5} \mathrm{D}_{0}$ radiative and nonradiative transition probabilities and the quantum efficiency, together with the number of water molecules in the $\mathrm{Eu}^{3+}$ first coordination shell, are collected in Table 4 for the as-synthesized, dehydrated and rehydrated materials. The results for the as-synthesized and rehydrated samples are very similar, indicating one water molecule in the coordination sphere of $\mathrm{Eu}^{3+}$, in accord with crystal structure. The increase observed in the ${ }^{5} \mathrm{D}_{0}$ lifetime upon dehydration (Table 3 ) is mainly due to a decrease in the nonradiative transition probability, promoted by the released of the coordinated water

(43) Carlos, L. D.; Messaddeq, Y.; Brito, H. M.; Ferreira, R. A. S.; de Zea Bermudez, V.; Ribeiro, S. J. L. Adv. Mater. 2000, 12, 594-598.

(44) Werts, M. H. V.; Jukes, R. T. F.; Verhoeven, J. W. Phys. Chem. Chem. Phys. 2002, 4, 1542-1548

(45) Supkowski, R. M.; Horrocks, W. D. W. J. Inorg. Chim. Acta 2002, 340, $44-48$.
Table 4. ${ }^{5} \mathrm{D}_{0}$ Radiative $\left(k_{\mathrm{r}}, \mathrm{s}^{-1}\right)$ and Nonradiative $\left(k_{\mathrm{nr}}, \mathrm{s}^{-1}\right)$ Transition Probabilities, the Quantum Efficiency $(q, \%)$, and the Estimated Number of Water Molecules $\left(n_{\mathrm{w}}\right)$ of As-Synthesized, Dehydrated, and Rehydrated 1e

\begin{tabular}{llll}
\hline & as-synthesized & dehydrated & rehydrated \\
\hline$k_{\mathrm{r}}$ & 0.407 & 0.426 & 0.410 \\
$k_{\mathrm{nr}}$ & 1.291 & 0.470 & 1.208 \\
$q$ & 24.0 & 47.6 & 25.4 \\
$n_{\mathrm{w}}$ & $1.1 \pm 0.1$ & $0.2 \pm 0.1$ & $1.0 \pm 0.1$ \\
\hline
\end{tabular}

molecule. This occurrence also increases the ${ }^{5} \mathrm{D}_{0}$ quantum efficiency from ca. 24 to ca. $47 \%$.

Vibrational Spectroscopy. Vibrational (FT-IR and FTRaman) spectroscopy studies of the framework (family 1) and layered materials (families 2, 3, and 4) clearly support the structural features unveiled from the X-ray diffraction studies. Figures S9-S11 in Supporting Information show selected FTIR and FT-Raman spectral regions for all compounds. In particular, the spectral regions in the $3600-3100 \mathrm{~cm}^{-1}$ (associated with the $\mathrm{O}-\mathrm{H}$ stretching vibrations) and $1200-900 \mathrm{~cm}^{-1}$ ranges (stretching modes associated with the $\mathrm{C}-\mathrm{O}$ and $\mathrm{P}-\mathrm{O}$ bonds) contain diagnostic bands which clearly illustrate the structural features associated with the different coordination modes of etidronic acid residues in the $2 \mathrm{D}$ and $3 \mathrm{D}$ materials, previously described in detail. ${ }^{46}$

In the framework-type materials, the FT-IR spectral regions between 3600 and $3100 \mathrm{~cm}^{-1}$ contain a broad band (peaking at about $\left.3400 \mathrm{~cm}^{-1}\right)$ that is attributed to the $v(\mathrm{O}-\mathrm{H})$ stretching vibrational mode of water molecules involved in hydrogen bonds. This spectral feature contrasts with that observed for all layered materials in which the same spectral region of the FTIR spectra is usually more complex with a number of different $v(\mathrm{O}-\mathrm{H})$ stretching vibrational modes arising from the water molecules, plus $\mathrm{CO}-\mathrm{H}$ and $\mathrm{PO}-\mathrm{H}$ from the etidronic acid residues (Figures S5 to S8 in Supporting Information). This is markedly visible in the spectrum of $\mathbf{2} \mathbf{a}$ where three bands are clearly observed in the $v(\mathrm{O}-\mathrm{H})$ stretching vibrational region: $3521 \mathrm{~cm}^{-1}$ (sh), $3443 \mathrm{~cm}^{-1}$ (br), and $3374 \mathrm{~cm}^{-1}$ (sh).

A number of intense and sharp bands appear in the 1200$900 \mathrm{~cm}^{-1}$ spectral region in both the FT-IR and FT-Raman spectra. Whereas the bands at higher wavenumbers (at about $1160 \mathrm{~cm}^{-1}$ ) are assigned to $v(\mathrm{C}-\mathrm{O})$, those in the lower wavenumber region (at about $920 \mathrm{~cm}^{-1}$ ) are attributed to the $v(\mathrm{P}-\mathrm{OH})$ vibrational mode and appear, as expected, only in the spectra of the 2D REOFs. Strong FT-IR and FT-Raman bands centered at ca. $1060 \mathrm{~cm}^{-1}$, plus two bands around 1020$990 \mathrm{~cm}^{-1}$ are attributed to $v_{\mathrm{as}}\left(\mathrm{P}-\mathrm{O}_{\text {coord }}\right)$ and $v_{\mathrm{s}}\left(\mathrm{P}-\mathrm{O}_{\text {coord }}\right)$, respectively, and are present in all spectra, thus clearly supporting the coordination of the phosphonate groups to the metallic centers. ${ }^{47}$

Thermal Analysis. Thermal treatment (in air) of frameworktype materials belonging to family $\mathbf{1}$ between ambient temperature and approximately $600{ }^{\circ} \mathrm{C}$ resulted in decomposition processes which exhibit a handful of slight differences (attributed to the distinct lanthanide centers) as clearly depicted by

(46) Socrates, G. Infrared Characteristic Group Frequencies - Tables and Charts, 2nd ed.; John Wiley \& Sons Ltd: Chichester, 1994.

(47) (a) Barja, B. C.; Herszage, J.; Alfonso, M. D. Polyhedron 2001, 20, 18211830. (b) Kong, D. Y.; Li, Y.; Xiang, O. Y.; Prosvirin, A. V.; Zhao, H. H. Ross, J. H.; Dunbar, K. R.; Clearfield, A. Chem. Mater. 2004, 16, 30203031. (c) Martinez-Tapia, H. S.; Cabeza, A.; Bruque, S.; Pertierra, P. Garcia-Granda, S.; Aranda, M. A. G. J. Solid State Chem. 2000, 151, 122129. 
the individual thermograms (Figure S12 in Supporting Information). However, detailed analysis of each thermogram reveals that members of this family ultimately decompose through similar overall processes, even though the number of individual weight losses and the temperature at which they occur vary according to the lanthanide center. Decomposition starts with the liberation of all water molecules (both housed in the channels and coordinated to the lanthanide centers), followed by the release of all carbon atoms of the $\mathrm{H}_{5}$ hedp residues. Even though a detailed knowledge of the chemical processes involving each decomposition step is unclear at present, from PXRD studies at high temperature of 1e (Figure 4), it is also feasible to assume that the residues at $600{ }^{\circ} \mathrm{C}$ for all members of family 1 might be composed of a mixture of $\mathrm{MPO}_{4}, \mathrm{NaPO}_{3}$ and $\mathrm{NaMP}_{2} \mathrm{O}_{7}$.

Each type of layered REOFs exhibits a different behavior for its thermal decomposition (see Figure S13 in Supporting Information for individual thermograms). Particularly, thermal analyses of members of family $\mathbf{3}$ clearly show that between ambient temperature and approximately $200{ }^{\circ} \mathrm{C}$ all water molecules located in the interlayer space and forming the aforementioned $\left(\mathrm{H}_{2} \mathrm{O}\right)_{13}$ cluster are readily released with observed total weight losses of ca. 14.6 and ca. $11.8 \%$ for $\mathbf{3 a}$ and $\mathbf{3 b}$, respectively, which agree well with the expected values (14.8 and $12.5 \%$, respectively). An identical behavior is registered for compound $\mathbf{4}$, but the kinetics associated with the liberation of the interstitial crystallographically independent water molecule is significantly slower with a continuous process being observed between ambient temperature and ca. $310{ }^{\circ} \mathrm{C}$ (weight loss of ca. 4.2\%; calculated ca. 4.6\%). After this initial release, decomposition in family 3 proceeds with the liberation of the remaining (coordinated) water molecule and the subsequent transformation of the organic component associated with the $\mathrm{H}_{2}$ hedp ${ }^{3-}$ residues.

\section{Conclusions}

A series of novel modular multidimensional lanthanideorganic frameworks built up from lanthanide centers and etidronic acid $\left(\mathrm{H}_{5}\right.$ hedp) have been prepared: framework-type $\mathrm{Na}_{2}\left[\mathrm{Y}(\right.$ hedp $\left.)\left(\mathrm{H}_{2} \mathrm{O}\right)_{0.67}\right]$ and $\left.\mathrm{Na}_{4}\left[\mathrm{Ln}_{2} \text { (hedp) }\right)_{2}\left(\mathrm{H}_{2} \mathrm{O}\right)_{2}\right] \cdot n \mathrm{H}_{2} \mathrm{O}$ [Ln $=\mathrm{La}, \mathrm{Ce}, \mathrm{Nd}, \mathrm{Eu}, \mathrm{Gd}, \mathrm{Tb}$, and Er], layered orthorhombic [Eu$\left(\mathrm{H}_{2}\right.$ hedp $\left.)\left(\mathrm{H}_{2} \mathrm{O}\right)_{2}\right] \cdot \mathrm{H}_{2} \mathrm{O}$ and $\mathrm{Na}_{0.9}\left[\mathrm{Nd}_{0.9} \mathrm{Ge}_{0.10}(\right.$ Hhedp $\left.)\left(\mathrm{H}_{2} \mathrm{O}\right)_{2}\right]$, monoclinic $\left[\mathrm{M}\left(\mathrm{H}_{2}\right.\right.$ hedp $\left.)\left(\mathrm{H}_{2} \mathrm{O}\right)\right] \cdot 3 \mathrm{H}_{2} \mathrm{O}[\mathrm{M}=\mathrm{Y}, \mathrm{Tb}]$, and triclinic $\left[\mathrm{Yb}\left(\mathrm{H}_{2}\right.\right.$ hedp $\left.)\right] \cdot \mathrm{H}_{2} \mathrm{O}$. The framework materials are among the few known to combine zeolite-type behavior with photoluminescence properties. Framework and layered materials are, to a certain extent, interconvertable via the hydrothermal treatment of the $3 \mathrm{D}$ or $2 \mathrm{D}$ REOFs with $\mathrm{HCl}$ or sodium chloride, respectively. Finally, in layered $\left[\mathrm{Y}\left(\mathrm{H}_{2}\right.\right.$ hedp $\left.)\left(\mathrm{H}_{2} \mathrm{O}\right)\right] \cdot 3 \mathrm{H}_{2} \mathrm{O}$, noncoordinated water molecules are engaged in cooperative water-to-water hydrogen-bonding interactions, leading to the formation of a $\left(\mathrm{H}_{2} \mathrm{O}\right)_{13}$ cluster, which is the basis of an unprecedented twodimensional water network.

Acknowledgment. We are grateful to Fundação para a Ciência e a Tecnologia (Portugal) for their general financial support (POCI/QUI/58377/2004 supported by FEDER), the postdoctoral scholarships Nos. SFRH/BPD/9309/2002 (to F.N.S.) and SFRH/BPD/14410/2003 (to L.C.-S.), and for funding toward the purchase of the single-crystal diffractometer. Financial support from NoE FAME is also acknowledged.

Supporting Information Available: X-ray crystallographic information for the compounds, additional structural drawings and schemes, SEM pictures, and crystallographic tables. ${ }^{1} \mathrm{H}-$ ${ }^{31} \mathrm{P}$ CP-MAS spectra for 1b. FT-IR, FT-Raman, and TG curves for all compounds belonging to family types $\mathbf{1}-\mathbf{4}$. This material is available free of charge via the Internet at http://pubs.acs.org.

JA074119K 